\title{
Trypanosoma cruzi Mitochondrial Peroxiredoxin Promotes Infectivity in Macrophages and Attenuates Nifurtimox Toxicity
}

\author{
Gabriela Specker, Damián Estrada, Rafael Radi and Lucía Piacenza* \\ Departamento de Bioquímica and Centro de Investigaciones Biomédicas (CEINBIO), Facultad de Medicina, Universidad de la \\ República, Montevideo, Uruguay
}

OPEN ACCESS

Edited by:

Tania F. De Koning-Ward,

Deakin University, Australia

Reviewed by:

Fred David Mast,

Seattle Children's Research Institute,

United States

Alexis Kaushansky,

University of Washington,

United States

*Correspondence:

Lucía Piacenza

Ipiacenza@fmed.edu.uy

Specialty section:

This article was submitted to

Parasite and Host,

a section of the journal

Frontiers in Cellular and

Infection Microbiology

Received: 29 July 2021 Accepted: 07 January 2022 Published: 04 February 2022

Citation:

Specker G, Estrada D, Radi R and Piacenza L (2022) Trypanosoma cruzi Mitochondrial Peroxiredoxin Promotes Infectivity in Macrophages and Attenuates Nifurtimox Toxicity. Front. Cell. Infect. Microbiol. 12:749476. doi: 10.3389/fcimb.2022.749476
Trypanosoma cruzi is the causative agent of Chagas disease which is currently treated by nifurtimox (NFX) and benznidazole (BZ). Nevertheless, the mechanism of action of NFX is not completely established. Herein, we show the protective effects of $T$. cruzi mitochondrial peroxiredoxin (MPX) in macrophage infections and in response to NFX toxicity. After a 3-day treatment of epimastigotes with NFX, MPX content increased (2.5fold) with respect to control, and interestingly, an MPX-overexpressing strain was more resistant to the drug. The generation of mitochondrial reactive species and the redox status of the low molecular weight thiols of the parasite were not affected by NFX treatment indicating the absence of oxidative stress in this condition. Since MPX was shown to be protective and overexpressed in drug-challenged parasites, non-classical peroxiredoxin activity was studied. We found that recombinant MPX exhibits holdase activity independently of its redox state and that its overexpression was also observed in temperature-challenged parasites. Moreover, increased holdase activity (2-fold) together with an augmented protease activity (proteasome-related) and an enhancement in ubiquitinylated proteins was found in NFX-treated parasites. These results suggest a protective role of MPX holdase activity toward NFX toxicity. Trypanosoma cruzi has a complex life cycle, part of which involves the invasion of mammalian cells, where parasite replication inside the host occurs. In the early stages of the infection, macrophages recognize and engulf $T$. cruzi with the generation of reactive oxygen and nitrogen species toward the internalized parasite. Parasites overexpressing MPX produced higher macrophage infection yield compared with wild-type parasites. The relevance of peroxidase vs. holdase activity of MPX during macrophage infections was assessed using conoidin $A(C A)$, a covalent, cell-permeable inhibitor of peroxiredoxin peroxidase activity. Covalent adducts of MPX were detected in CA-treated parasites, which proves its action in vivo. The pretreatment of parasites with CA led to a reduced infection index in 
macrophages revealing that the peroxidase activity of peroxiredoxin is crucial during this infection process. Our results confirm the importance of peroxidase activity during macrophage infection and provide insights for the relevance of MPX holdase activity in NFX resistance.

Keywords: $T$. cruzi, nifurtimox, mitochondrial peroxiredoxin, macrophage infection, holdase and peroxidase activities

\section{INTRODUCTION}

Trypanosoma cruzi (T. cruzi) is the intracellular parasite that causes Chagas disease, which is considered a neglected disease and remains a public health problem in Latin America, estimated to affect approximately 6 million people and with 70 million at risk of infection (Pérez-Molina and Molina, 2018). Trypanosoma cruzi has a complex life cycle that involves two hosts, the insect vector and the vertebrate host, and four stages of the parasite. The replicative, non-infective epimastigote stage is found in the insect midgut and, during its migration to the hindgut, differentiates to the infective, non-replicative metacyclic trypomastigotes that can invade different vertebrate cells. Inside cells, trypomastigote transforms into the infective, replicative intracellular amastigote. Following several rounds of replication, the infective blood trypomastigote escapes and disseminates the infection to other tissues. During the life cycle, parasite survival depends on its rapid and efficient adaptation to the distinct environments faced, which is accomplished by extensive biochemical and morphological changes. Trypanosoma cruzi is a heterogeneous species, with large genetic variability and different strains that circulate between the vertebrate host and the insect vector. This heterogeneity may explain the variation in the clinical manifestation of Chagas disease and the geographical differences in morbidity and mortality (Laurent et al., 1997; Da Silva Manoel-Caetano and Silva, 2007; McCall and McKerrow, 2014).

Activation of professional phagocytes (macrophages and neutrophils) with the concomitant generation of oxidant species is a medullar innate immune process for the control of acute T. cruzi infection. Recent data reinforce the hypothesis that parasites more prepared to deal with the host-oxidative assault are more efficient for the establishment of the infection (Piacenza et al., 2009a; Alvarez et al., 2011; Martinez et al., 2014; Estrada et al., 2018; Piacenza et al., 2019). Nevertheless, T. cruzi contains a complex system of antioxidant enzymes and related proteins that allows it to overcome the oxidants, produced by the host immune response (Wilkinson et al., 2000; Mateo et al., 2008; Piacenza et al., 2009b; Wilkinson et al., 2002a; Wilkinson et al., 2002b; Wilkinson et al., 2002c). This antioxidant system has multiple components distributed in all parasite subcellular compartments, where they maintain the redox balance playing a key role in parasite virulence and persistence in tissues (Piacenza et al., 2013; Estrada et al., 2018; Piacenza et al., 2019).

Peroxide metabolism in T. cruzi relies on five peroxidases located in different subcellular compartments: heme-containing cytochrome c ascorbate peroxidase, two glutathione-like peroxidases and two peroxiredoxins, ubiquitous peroxidases that depend on cysteine residues to reduce peroxides (Wilkinson et al., 2000; Wilkinson et al., 2002a; Wilkinson et al., 2002b; Wilkinson et al., 2002c; Hugo et al., 2017). Both the cytosolic (CPX) and the mitochondrial peroxiredoxin (MPX) are two cysteine-typical peroxiredoxins which use tryparedoxin (TXN) as reducing substrate. The oxidized TXN is then reduced by trypanothione $\left[\mathrm{T}(\mathrm{SH})_{2}\right]$, a low molecular weight thiol unique to trypanosomatids, at the expense of NADPH. Trypanosoma cruzi peroxiredoxins are able to detoxify $\mathrm{H}_{2} \mathrm{O}_{2}$, peroxynitrite $(\mathrm{ONOOH})$, and short-chain organic hydroperoxides $(\mathrm{ROOH})$, and its level of expression has been correlated with the virulence of different strains (Wilkinson et al., 2000; Trujillo et al., 2004; Piñeyro et al., 2008; Piacenza et al., 2009b). In most two cystypical peroxiredoxins, such as MPX and CPX, the basic functional unit is the dimer, but generally, they are able to establish higher-order structures specifically as octameric, decameric, and dodecameric toroids (Cao and Lindsay, 2017). In recent years, it has been described in many organisms that peroxiredoxins, besides its function as peroxidases, have other activities such as holdase and as part of signaling pathways (Rhee et al., 2012; Perkins et al., 2015; Sobotta et al., 2015). Holdases are part of the molecular chaperone family which prevents aggregation of proteins in an ATP-independent manner (Folgueira and Requena, 2007; Kim et al., 2013). Holdase activity is crucial for cellular protection during different stress conditions that induces protein damage and unfolding with the possible formation of protein aggregates. The interplay between the peroxidase and holdase function of peroxiredoxins is regulated by several environments in the cell such as $\mathrm{pH}$, temperature, ions, posttranslational modifications, and redox balance (Jang et al., 2006; Saccoccia et al., 2012; Morais et al., 2017a). Moreover, holdase activity seems to be related to the oligomeric state of the enzyme, taking into consideration that holdase activity is mainly reported in decameric or higher molecular weight oligomers, which means that conditions that favor the said structure will stimulate this activity in peroxiredoxins. It is proposed that oligomerization dynamics and, therefore, holdase function are dependent on the redox state of the cell, given that oxidized forms of peroxiredoxins, which have mainly dimeric conformations, do not exhibit holdase activity, whereas their reduced or overoxidized forms, which form decamers and/or higher molecular weight oligomers, display holdase activity (Wood et al., 2002; Wood et al., 2003; Rhee and Woo, 2011; Perkins et al., 2015). However, there are reports that also show that oxidized peroxiredoxins are able to acquire high molecular weight conformations, and thus, the precise relationship between redox state and holdase activity 
will depend on the specific peroxiredoxin under study (Yewdall et al., 2016). Regarding these novel functions, it was found that $T$. cruzi CPX has the ability to prevent aggregation of malate dehydrogenase in vitro independently of its redox state (Piñeyro et al., 2019). Furthermore, the crystal structure of the CPX is available and shows that it is a toroid-shaped decamer in its active and reduced form (Piñeyro et al., 2005), like most peroxiredoxins that act as holdases. It was shown that this peroxiredoxin does not disassemble into dimers upon oxidation. Nonetheless, it has not been yet proven in vivo that T. cruzi peroxiredoxins have holdase activity. In Leishmania infantum, another trypanosomatid with long-lasting residence in the macrophage phagosome, it has been reported that mitochondrial peroxiredoxin (LiPrxlm) presents holdase activity in vitro and that a deficiency in this enzyme yields parasites more sensitive to a rise in temperature (Castro et al., 2011). These deficient parasites also presented a decreased survival in macrophages, but interestingly, they could be rescued by the expression of the $L i \operatorname{Prx} 1 \mathrm{~m}$ in which the peroxidatic cysteine $(\mathrm{Cp})$ was absent, indicating that other activity than the classical peroxidase (i.e., holdase) is involved in protecting amastigotes to macrophage-derived stressors (Castro et al., 2011; Teixeira et al., 2015).

Treatment of Chagas disease relies mainly on two old and poorly specific chemotherapeutic agents: benznidazole (BZ) and nifurtimox (NFX). These drugs have several disadvantages; they are only effective in the acute phase of the disease, treatment may last for months with important side effects, and there are resistant strains (Rassi et al., 2010). Both of these drugs are nitroheterocycle compounds: NFX is a nitrofurane derivative, while $\mathrm{BZ}$ is a nitroimidazole. The mode of action of NFX is still elusive and two major mechanisms have been proposed, which agree in the fact that NFX has to be metabolized to act as an antitrypanosomatid drug. First, NFX toxicity was explained by NFX redox cycling with superoxide radical $\left(\mathrm{O}_{2}{ }^{--}\right)$and $\mathrm{H}_{2} \mathrm{O}_{2}$ production (Docampo and Stoppani, 1979; Docampo and Moreno, 1984), with a concomitant increase in oxidative stress within the parasite. The drug was thought to be activated by one electron reduction catalyzed by type II nitroreductase (NTR-II), producing nitrofurane radical, that in aerobic conditions gives rise to a futile cycle that results in regeneration of the nitro group and production of $\mathrm{O}_{2}{ }^{--}$which dismutate to $\mathrm{H}_{2} \mathrm{O}_{2}$ and $\mathrm{O}_{2}$ catalyzed by superoxide dismutases (SODs) in a diffusion-controlled reaction (McCord and Fridovich, 1969). This postulation is based on the observation that after NFX treatment, parasite extracts showed an increased oxygen consumption and production of $\mathrm{O}_{2}{ }^{--}$as well as in the fact that Trypanosoma brucei strains deficient in cytosolic iron SOD (TbSODB1) showed more sensitivity toward NFX (Roberto Docampo and Stoppani, 1979; Prathalingham Radhika et al., 2007). Moreover, it was reported that treatment with NFX leads to depletion of the principal low molecular weight thiols of the parasite, although it was discussed that this could be explained by redox cycling of the drug or by conjugation of thiols with drug metabolites (Maya et al., 1997).

The second mechanism relies on the activation of NFX by a parasite NADH-dependent mitochondrial type I nitroreductase
(NTR-I), insensitive to $\mathrm{O}_{2}$, that has FMN as cofactor and catalyzes sequential 2-electron reduction steps to yield unsaturated open chain nitriles that have trypanocidal activities with no significant generation of oxidative stress (Boiani et al., 2010; Hall et al., 2011). Trypanosoma cruzi-resistant strains have only one copy of TcNTR-I gene, and genetic modification of parasites to give knockout or overexpressers resulted in resistant or hypersensitive parasites to NFX, respectively. This shows a connection between NTR-I activity and nifurtimox toxicity (Wilkinson et al., 2008; Cerecetto and González, 2011).

Taking into consideration the abovementioned results related to the peroxiredoxins of trypanosomatids and its different functions within the cell, we evaluated the ability of T. cruzi mitochondrial peroxiredoxin to act as holdase and studied the relative weight of both activities (peroxidase and holdase) toward macrophage and NFX-derived toxicity. The results presented herein contribute to the understanding of the role of T. cruzi mitochondrial peroxiredoxin in response to different stress, gaining insights into the redox and holdase function of this peroxidase.

\section{RESULTS}

\section{Parasites Overexpressing MPX Are More Resistant to NFX Toxicity}

In order to evaluate the influence of MPX content in parasites on NFX toxicity, the growth curves of epimastigotes in the absence or presence of the drug in a concentration close to its $\mathrm{IC}_{50}(7 \mu \mathrm{M})$ were performed (Boiani et al., 2010). WT and genetically transformed parasites to overexpress MPX (Supplementary Figure S1) (Piacenza et al., 2008) showed a similar growth profile in control conditions (Figure 1 and Supplementary Figure S2), whereas in the presence of NFX, MPX-overexpressing parasites showed an increased resistance to the toxic effects of the drug compared with WT parasites (Figure 1A, upper and lower panels). Since MPX is able to detoxify different peroxides and taking into account that this species may be generated during the early stages of NFX metabolism in some circumstances, we searched for the generation of reactive oxygen species following dihydrorhodamine (DHR) oxidation. Parasites treated for $2 \mathrm{~h}$ with the drug were loaded with DHR and the formation of RH123, the oxidized product, was evaluated. No increase in probe oxidation was observed in our experimental conditions (Figure 1B). Parasite treatment with $\mathrm{H}_{2} \mathrm{O}_{2}(300 \mu \mathrm{M})$ for $30 \mathrm{~min}$ was previously shown to increase intramitochondrial superoxide radical generation (Estrada et al., 2018) and was used herein as a positive control. Increased DHR oxidation was observed in $\mathrm{H}_{2} \mathrm{O}_{2}$-treated parasites, and this was significantly enhanced when parasites were previously $(24 \mathrm{~h})$ incubated in the presence of buthionine-S,R-sulfoximine (BSO), an inhibitor of GSH synthesis (Griffith and Meister, 1979; Meister, 1995). In this condition, overexpression of MPX leads to a significantly lower DHR oxidation with respect to WT parasites (Figure 1B). The levels of non-protein thiols [i.e., $\mathrm{GSH}$ and $\mathrm{T}(\mathrm{SH})_{2}$ ] were evaluated daily during the growth curve in non-treated and NFX-treated parasites by $\mathrm{mBrBm}$ derivatization and HPLC-fluorescent detection (Figure 1C). GSH 

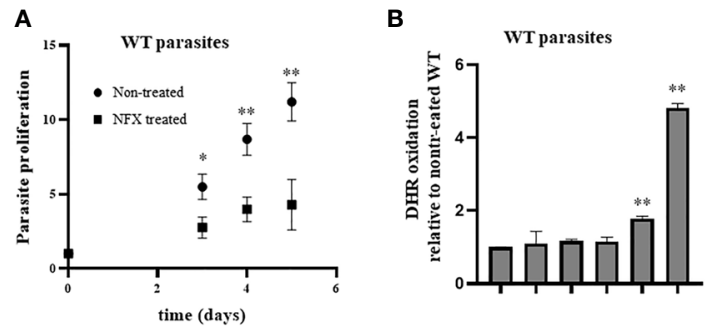

C
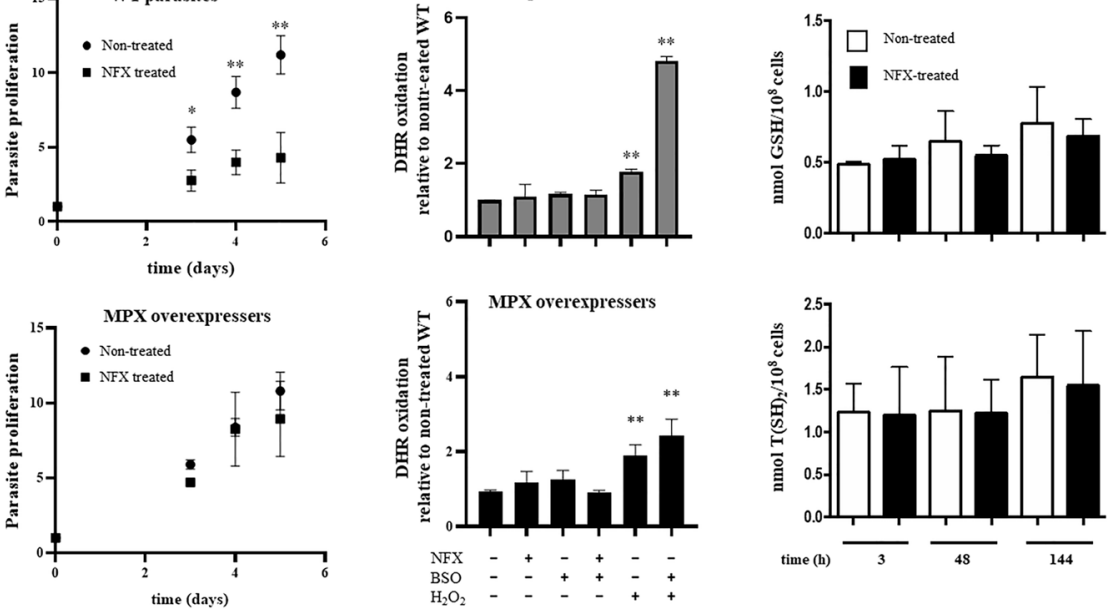

FIGURE 1 | The protective role of mitochondrial peroxiredoxin (MPX) toward nifurtimox (NFX) in epimastigotes without modifying redox state. (A) Growth curve of epimastigotes wild type (WT) (upper panel) and MPX-overexpressing parasites (lower panel) in the absence or presence of NFX (7 $\mu \mathrm{M})$. Parasites were cultured in BHI medium at $28^{\circ} \mathrm{C}$ and cell density was evaluated every day by absorbance at $600 \mathrm{~nm}$. * denotes statistical differences $(p<0.05)$ and ${ }^{* \star}$ statistical differences $(p<0.01)$ compared with non-treated (two-tailed unpaired t-test). (B) Dihydrorhodamine (DHR) oxidation. Non-treated or overnight BSO-treated parasites were preloaded with DHR $(50 \mu \mathrm{M})$ and exposed either to NFX (7 $\mu \mathrm{M}, 2 \mathrm{~h})$ or $\mathrm{H}_{2} \mathrm{O}_{2}(300 \mu \mathrm{M}, 30$ min). DHR oxidation was measured in a fluorescence plate reader (Varioskan Flash, Thermo Scientific) at $\lambda_{\mathrm{ex}}=485 \mathrm{~nm}$ and $\lambda_{\mathrm{em}}=520 \mathrm{~nm}$. Upper panel: DHR oxidation in WT parasites. Lower panel: DHR oxidation in parasites overexpressing MPX. Results are expressed as fluorescence units with respect to non-treated WT condition. ${ }^{* *}$ denotes statistical differences $(p<0.01)$ compared with non-treated condition (two-tailed unpaired $t$-test). (C) The content of reduced low molecular weight (LMW) thiols in WT epimastigotes $\left(1 \times 10^{8}\right.$ cells) incubated for different times with NFX (7 $\mu$ M) was determined by HPLC as described. Upper panel: Quantification of GSH in non-treated (white bars) and NFX-treated WT parasites (black bars) at different times. Lower panel: Quantification of $\mathrm{T}(\mathrm{SH})_{2}$ in non-treated (white bars) and NFX-treated WT parasites (black bars). Results are expressed as nmol thiol/10 ${ }^{8}$ parasites.

$\left(0.6 \pm 0.2 \mathrm{nmol} / 10^{8}\right.$ cells $)$ and $\mathrm{T}(\mathrm{SH})_{2}\left(1.6 \pm 0.6 \mathrm{nmol} / 10^{8}\right.$ cells $)$ remain unchanged during the 5-day incubation with NFX with intracellular levels in the order of that previously reported (Thomson et al., 2003). Overall, our results suggest that in our experimental conditions, NFX is not generating a redox cycle with the production of reactive oxygen species, and thus, the protective effects observed in MPXoverexpressing parasites seem not to be ascribable to its peroxidase activity. Moreover, since it was proposed that NFX is activated at the parasite mitochondria, we examined the mitochondrial membrane potential after a 3-day parasite culture with the drug by rhodamine-123 incorporation and the site-specific generation of $\mathrm{O}_{2}{ }^{--} / \mathrm{H}_{2} \mathrm{O}_{2}$ by MitoSOX oxidation (Figure 2). NFX treatment of WT parasites caused a significant decrease $(30 \%)$ of mitochondrial membrane potential with respect to non-treated parasites, whereas no changes in mitochondrial membrane potential were observed for MPX-overexpressing parasites (Figure 2A). FCCP, a mitochondrial uncoupler, was used as a positive control of mitochondrial depolarization. Finally, MitoSOX oxidation was evaluated in parasites following a 2 -h incubation with NFX, and also, non-detectable oxidation of the probe was observed in drug-treated parasites. Parasite treatment with $\mathrm{H}_{2} \mathrm{O}_{2}$ as described above $(300 \mu \mathrm{M}, 30 \mathrm{~min})$ was used as a positive control (Figure 2B), given that this treatment leads to mitochondrial superoxide radical generation (Estrada et al., 2018). The results presented herein suggest that enhanced content of MPX protects parasites for the NFX toxicity at the mitochondrial compartment.

\section{NFX Induces Enhanced MPX Protein Expression in WT Parasites}

The content of MPX in WT parasites was evaluated following a 3-day treatment with NFX (7 and $14 \mu \mathrm{M})$. As shown in Figures 3A, B, MPX expression was significantly increased in NFX-treated parasites in a dose-dependent manner (2.5- and 3.5 -fold increase) strengthening the hypothesis of a protective role of this enzyme toward the damage exerted by NFX. No changes in protein content were observed in the cytosolic peroxiredoxin (CPX) and other T. cruzi peroxiredoxin with holdase activity in vitro (Figure 3C) (Piñeyro et al., 2019) in agreement with the mitochondrial activation of NFX. Interestingly, NFX treatment leads to the generation of nonreducible (with freshly prepared DTT or phosphine) dimers and higher aggregates that were not observed with $\mathrm{H}_{2} \mathrm{O}_{2}$ treatment (Figures 3A, B, arrows). Moreover, an increase in MPX content and the same non-reducible MPX dimers were observed after a temperature challenge by growing parasites at $37^{\circ} \mathrm{C}$ for 3 days (Figure 3B, arrows). This shift in temperature occurs during the life cycle of $T$. cruzi when the insect-derived metacyclic trypomastigotes $\left(28^{\circ} \mathrm{C}\right)$ invade the vertebrate host $\left(37^{\circ} \mathrm{C}\right)$. Furthermore, in order to evaluate if the increase in MPX content is also induced by other anti-T. cruzi drugs (BZ, azasterol, ketoconazole), parasites were incubated for 3 days with the $\mathrm{IC}_{50}$ of each drug. Only BZ treatment enhanced the MPX content (Supplementary Figure S4) in agreement with its mitochondrial-dependent NTR-I activation. BZ toxicity has been 


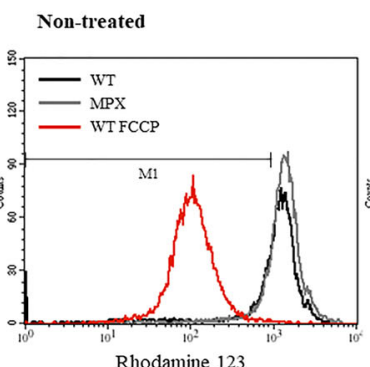

\section{NFX-treated}
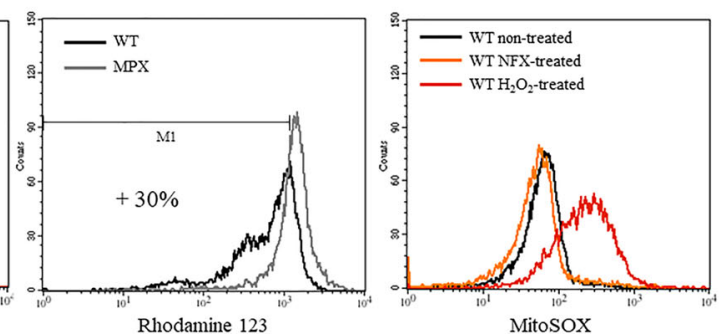

FIGURE 2 | Overexpression of MPX prevents loss of mitochondrial membrane potential in epimastigotes treated with NFX. (A) Evaluation of the mitochondrial membrane potential of epimastigotes WT and MPX overexpressers without treatment (left histogram) or treated with NFX (7 $\mu \mathrm{M}, 2$ h, right histogram) performed with the mitochondrial probe $\mathrm{RH} 123$ by flow cytometry. $\mathrm{FCCP}$ was used as a control of mitochondrial depolarization (left panel). (B) Parasite mitochondrial $\mathrm{O}_{2}{ }^{\bullet-} / \mathrm{H}_{2} \mathrm{O}_{2}$ generation was evaluated by MitoSOX oxidation and analyzed by flow cytometry. Following NFX treatment $(7 \mu \mathrm{M}, 2 \mathrm{~h})$ or not (non-treated), epimastigotes were washed with PBS and loaded with MitoSOX (5 $\mu \mathrm{M}, 30 \mathrm{~min})$, washed with PBS, and analyzed. The positive control was achieved by treating parasites with $\mathrm{H}_{2} \mathrm{O}_{2}$ (300 $\mu \mathrm{M}, 10 \mathrm{~min})$, then washed and loaded with the probe.
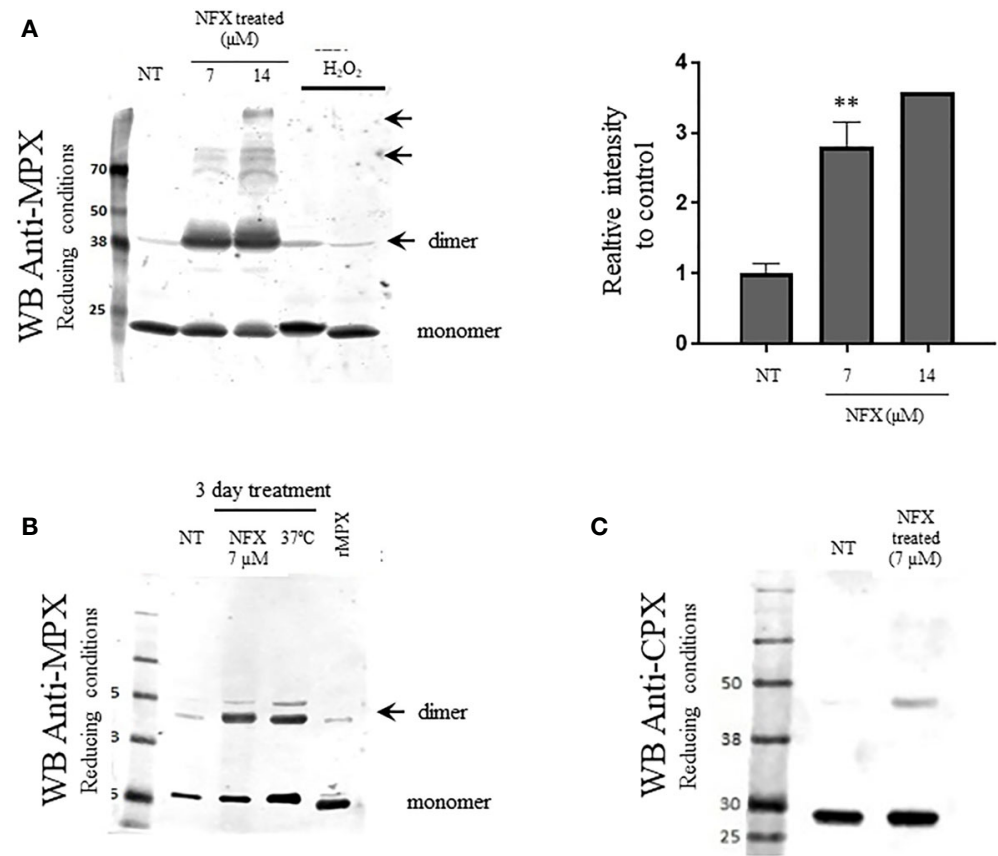

FIGURE 3 | Increased expression of MPX but not cytosolic peroxiredoxin (CPX) in WT parasites exposed to NFX. (A) Epimastigotes (WT) were grown in the absence or presence of NFX (7-14 MM, 3 days). After treatment, parasites $\left(1 \times 10^{8}\right.$ cells) were collected, washed, and resuspended in PBS buffer containing NEM (10 mM). Total protein extract $(50 \mu \mathrm{g})$ was run on SDS-PAGE (12\%) under reducing conditions (DTT, $1 \mathrm{mM}$ ) and Western blot for MPX and CPX was performed as described. Parasites incubated with $\mathrm{H}_{2} \mathrm{O}_{2}(300 \mu \mathrm{M}, 30 \mathrm{~min})$ was performed as control. Right panel: Relative quantification of band intensity with respect to control condition. Results are means \pm SEM of relative densitometric quantitation by LI-COR Image Studio of at least three independent determinations; *夫 denotes statistical differences $(p<0.01)$. For quantification, Coomassie blue staining of the different samples $(50 \mu \mathrm{g})$ was used as loading control (Supplementary Figure S3). NT, non-treated. NFX: treated 3 days with NFX 7 or $14 \mu \mathrm{M}$. $\mathrm{H}_{2} \mathrm{O}_{2}$ : treated with $\mathrm{H}_{2} \mathrm{O}_{2} 300 \mu \mathrm{M}$ for 10 min. (B) Evaluation of mitochondrial MPX content in parasites grown for 3 days in the presence of NFX [as in panel (A)] or at $37^{\circ} \mathrm{C}$. Western blot anti-MPX of protein extract was performed as in panel (A). Recombinant MPX (rMPX, $5 \mu \mathrm{g}$ ) was run as control. NT, non-treated. NFX: treated 3 days with NFX $7 \mu \mathrm{M} .37^{\circ} \mathrm{C}$ : grown 3 days at $37^{\circ} \mathrm{C}$. MPXr, recombinant MPX. (C) Western blot anti-CPX of protein extract of control parasites or grown in the presence of NFX, performed as in panel (A). NT, non-treated. NFX: treated 3 days with NFX $7 \mu \mathrm{M}$. 
proposed to occur via reduced intermediates that covalently modified low molecular weight thiols and different macromolecules with no generation of reactive oxygen species (Trochine et al., 2014). The above results ruled out the generation of oxidative stress after NFX treatment, and we aimed to evaluate the protective role of the MPX holdase activity.

\section{Trypanosoma cruzi Mitochondrial Peroxiredoxin Exhibits Holdase Activity}

To assess whether MPX is able to function as holdase, preventing protein aggregation, it was first tested if recombinant enzyme could enhance the refolding of GFP. This fluorescent protein loses its structure after a short incubation at low $\mathrm{pH}$ and, therefore, its fluorescence properties. GFP can refold and regain its fluorescent structure at a slow rate in the absence of holdases; however, when the refolding buffer is supplemented with a protein that can act as a holdase, the process of refolding is accelerated (Mares et al., 2011). As shown in Figure 4A, the presence of recombinant MPX (rMPX, $50 \mu \mathrm{M})$ causes GFP $(0.5 \mu \mathrm{M})$ to recover its fluorescence more efficiently. As a control condition, incubation of unfolded GFP with an unrelated protein that lacks holdase activity [bovine serum albumin (BSA), $50 \mu \mathrm{M}$ ) did not accelerate GFP refolding (Figure 4A). In case of MPX, as described also for CPX (Piñeyro et al., 2019), holdase activity is not dependent on its redox state since both reduced and oxidized $\mathrm{rMPX}$ and the mutant lacking the peroxidatic cysteine (Supplementary Figure S5) exhibit holdase activity (Figure 4B).

Holdase activity of some peroxiredoxins may rely on the gaining of higher structure levels with the formation of high molecular weight aggregates (Wood et al., 2003; Jang et al., 2004). In this sense, we evaluated whether parasite MPX could acquire high molecular weight aggregates after NFX incubation ( $7 \mu \mathrm{M}, 3$ days). For this purpose, the protein extracts from nontreated and NFX-treated parasites were separated on native $8 \%$ polyacrylamide gels and subjected to Western blot with anti-MPX antibody. As shown in Figure 5A, NFX and/or temperature treatment $\left(37^{\circ} \mathrm{C}, 3\right.$ days) leads to the formation of high molecular weight aggregates of MPX that were not observed in non-treated parasites. Then, we enriched the parasites extracts (NFX-treated or not) in high molecular protein or protein aggregates $(>100 \mathrm{kDa})$ and used these enriched extracts to search for MPX holdase activity in order to establish if NFX treatment could lead MPX to gain this function. As seen in Figure 5B, this high molecular weight extract obtained from WT parasites treated with NFX displayed an enhancement in holdase activity with respect to non-treated parasites. In the MPX-overexpressing parasites, no difference in holdase activity was observed between non-treated and NFX-treated parasite extracts (Figure 5C). This result indicates that NFX treatment of WT parasites causes MPX to enhance its expression and to gain holdase activity probably due to NFX-induced mitochondrial protein mis-/unfolding and that this function is related to the protective role of MPX toward NFX. In this line, NFX-treated parasites presented enhanced levels of protein ubiquitination (Figure 6A) and a significant increase in the mitochondrial proteosome-related protease activity (Figure 6B), suggesting that mitochondrial protein damage is being elicited by NFX metabolism.

\section{Selective Inhibition of MPX Peroxidase But Not Holdase Activity by Conoidin A}

With the aim to evaluate the role of peroxidase vs. holdase activity of MPX during macrophage infections, we examined the effects of conoidin A (CA), a previously reported cell-permeable covalent inhibitor of the peroxidase activity of some peroxiredoxins, by alkylating or crosslinking the catalytic cysteines (Liu et al., 2010; Brizuela et al., 2014). We first search for the ability of CA $(100 \mu \mathrm{M}, 1 \mathrm{~h})$ to produce MPX crosslinking. As shown in Figure 7A, Western blot of recombinant MPX treated for $1 \mathrm{~h}$ with $\mathrm{CA}(100 \mu \mathrm{M})$ revealed the presence of nonreducible aggregates of MPX indicating that CA reacts and crosslinks recombinant MPX. Then, peroxidase activity of recombinant pre-reduced $\mathrm{rMPX}(5 \mu \mathrm{M})$, control or previously incubated with CA $(100 \mu \mathrm{M})$, was followed by the inhibition of
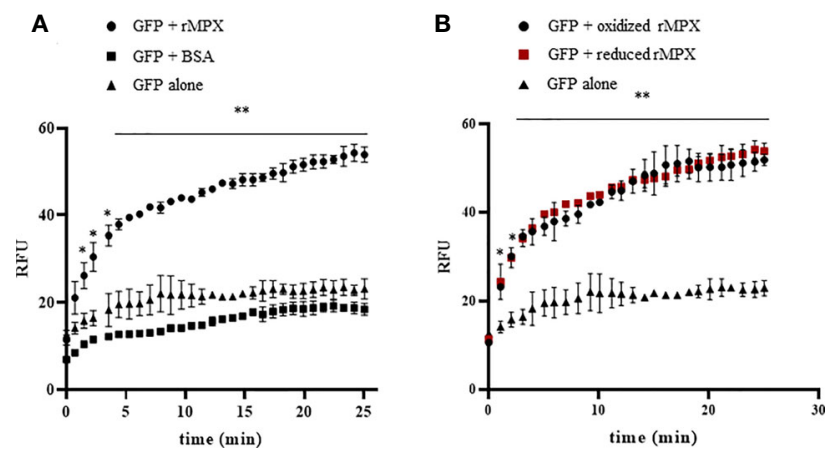

FIGURE 4 Holdase activity of recombinant MPX. (A) Holdase activity of recombinant MPX (rMPX) was evaluated with the GFP refolding assay as described in the Materials and Methods section. GFP was incubated in refolding buffer alone or in the presence of recombinant MPX (rMPX, $50 \mu \mathrm{M})$ or BSA (50 $\mu \mathrm{M}) .{ }^{\star}$ denotes statistical differences $(p<0.05)$ and ${ }^{* \star}$ statistical differences $(p<0.01)$ compared with GFP alone (two-tailed unpaired $t$-test). (B) Holdase activity of recombinant MPX $(\mathrm{rMPX}, 50 \mu \mathrm{M})$ in its reduced (DTT, $1 \mathrm{mM})$ and oxidized state. * Denotes statistical differences $(p<0.05)$ and ${ }^{* *}$ statistical differences $(p<0.01)$ compared with GFP alone (two-tailed unpaired $t$-test). There were no statistical differences between reduced and oxidized MPX. 


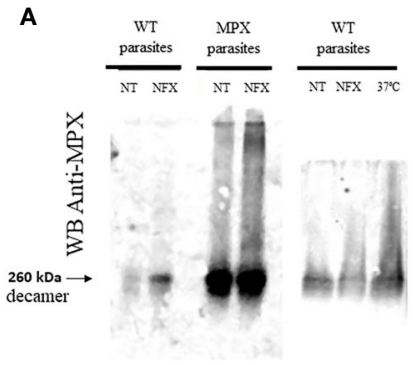

B

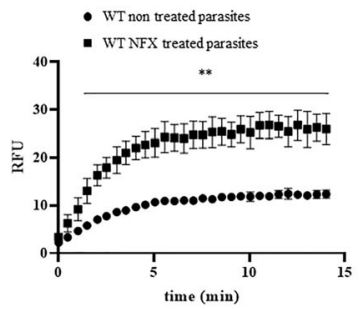

C

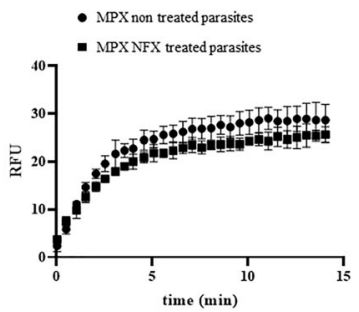

FIGURE 5 | Holdase activity of parasite MPX. (A) Mitochondrial peroxiredoxin ability to acquire high molecular weight aggregates in parasite was studied by native gel electrophoresis (8\%) and Western blot anti-MPX of total protein extract (obtained as in Figure 3,50 $\mu \mathrm{g}$ ) of WT or MPX-overexpressing parasites grown in the absence (non-treated, NT) or presence of NFX (NFX-treated, $7 \mu \mathrm{M}, 3$ days; left panel) or at $37^{\circ} \mathrm{C}$ (grown 3 days at $37^{\circ} \mathrm{C}$; right panel). NT, non-treated. NFX: treated 3 days with $\mathrm{NFX} 7 \mu \mathrm{M} .37^{\circ} \mathrm{C}$ : grown 3 days at $37^{\circ} \mathrm{C}$. (B, C) High molecular weight protein extract $(>100 \mathrm{kDa})$ was obtained from epimastigotes $\left(1 \times 10^{9}\right)$ non-treated or treated with NFX ( $7 \mu \mathrm{M}, 3$ days) as described in the Materials and Methods section. Level of holdase activity in high molecular weight fraction (300 $\mu \mathrm{g})$ was assessed by GFP refolding assay. (B) WT parasite extracts, non-treated and treated with NFX. (C) MPX-overexpressing parasite extracts non-treated and treated with NFX. ${ }^{* \star}$ denotes statistical differences $(p<0.01)$ compared with WT non-treated parasite extracts (two-tailed unpaired $t$-test). There were no statistical differences between extracts from MPX parasites non-treated and treated with NFX.
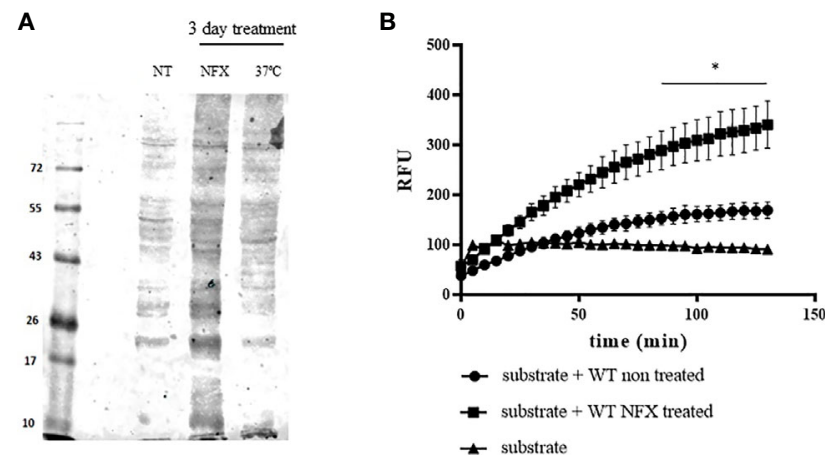

FIGURE 6 | Increased protein ubiquitination and mitochondrial protease activity in WT parasites treated with NFX. (A) Evaluation of proteins conjugated to ubiquitin in WT parasites non-treated (NT) or treated with NFX ( $7 \mu \mathrm{M}, 3$ days) or grown at $37^{\circ} \mathrm{C}$ ( 3 days). Following treatment, parasites were collected by centrifugation and washed in PBS, and the protein extract was obtained as described. Total protein extract $(50 \mu \mathrm{g})$ was run on SDS-PAGE (12\%) and Western blot anti-ubiquitin (Abcam/ab7780) was performed. (B) Protein extracts derived from parasites $\left(1 \times 10^{8}\right)$ grown in the absence or presence of NFX were tested for proteosome-related protease activity. Total protein extracts $(300 \mu \mathrm{g})$ were incubated at $28^{\circ} \mathrm{C}$ in buffer Tris- $\mathrm{HCl} \mathrm{pH} 7.4$ containing $50 \mu \mathrm{M}$ of the fluorogenic substrate Suc-Leu-Leu-ValTyr-AMC $(50 \mu M)$. AMC release was followed fluorometrically at $\lambda_{\mathrm{ex}}=365 \mathrm{~nm}$ and $\lambda_{\mathrm{em}}=440 \mathrm{~nm}$. * denotes statistical differences $(p<0.05)$ compared with WT nontreated parasite extracts (two-tailed unpaired $t$-test).

boronate oxidation $(\mathrm{CBA}, 50 \mu \mathrm{M})$ in the presence of controlled fluxes of peroxynitrite generated by SIN-1 (3.5 $\mu \mathrm{M} \mathrm{ONOO}^{-}$/ min). We took advantage of the practicality of evaluating peroxidase activity through this fast and simple assay, given that peroxynitrite is a key mediator of parasite control in the context of infection (Alvarez et al., 2011). MPX was able to inhibit ONOOH-dependent CBA oxidation ( 100 s, arrow), whereas when MPX was previously incubated with CA, peroxidase activity was inhibited, and CBA oxidation occurred with practically the same characteristics as when MPX was not added to the assay (Figure 7B). Finally, holdase activity was evaluated in MPX previously incubated with CA, which showed the same ability to aid in the GFP refolding than that of non- treated reduced MPX. Thus, CA treatment was unable to inhibit holdase activity, confirming that CA inhibits peroxidase but not holdase activity in recombinant MPX.

\section{MPX Peroxidase Activity Is Important for Parasite Survival in Macrophage Infections}

In order to clearly state the role of MPX peroxidase activity during macrophage invasion, we performed infection experiments in naive and immunostimulated macrophages for peroxynitrite generation. As shown in Figure 8A, overexpression of MPX rises by 2 -fold the ability of parasites to establish the infection in both naive and activated macrophages. This result indicates the crucial role of MPX for parasite survival. In order to discriminate the relative weight of 

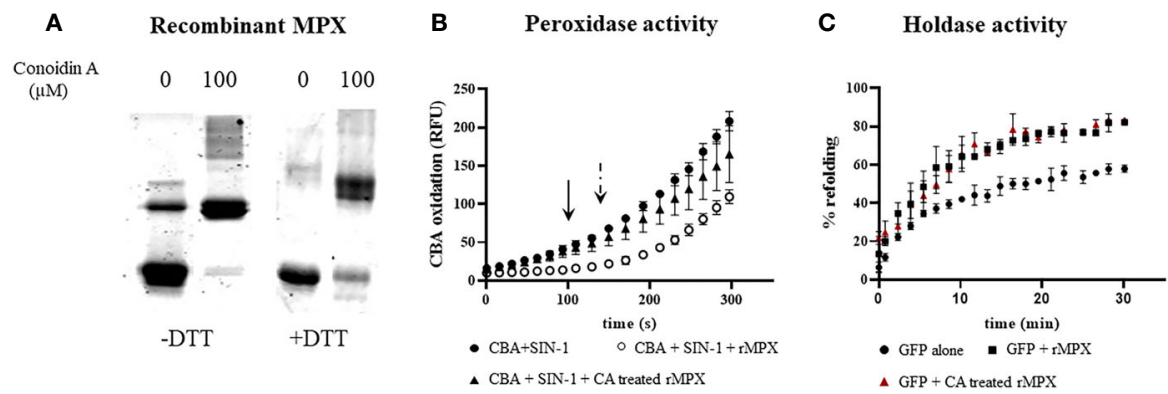

FIGURE 7 | Peroxidase but not holdase activity inhibition by conoidin A on recombinant MPX. (A) Recombinant MPX (5 $\mu$ M) treated with conoidin A as described in the Materials and Methods section. Samples were run on SDS-PAGE (12\%) under reducing (DTT, $1 \mathrm{mM}$ ) or non-reducing conditions. Coomassie blue staining is shown. Conoidin A resulted in the formation of non-reducible adducts of MPX. (B) Measurement of peroxidase activity of previously reduced MPX (5 $\mu$ M) control or incubated with conoidin A by its ability to decompose peroxynitrite produced by SIN-1 ( $2 \mathrm{mM}, 3 \mu \mathrm{M} / \mathrm{min})$, in the presence of CBA (50 $\mu \mathrm{M})$. CBA oxidation was followed fluorometrically at $\lambda_{\mathrm{ex}}=365 \mathrm{~nm}$ and $\lambda_{\mathrm{em}}=440 \mathrm{~nm}$. Arrow indicates the time lapse for non-treated MPX peroxynitrite detoxification (i.e., $\sim 100 \mathrm{~s}$ ), and dotted arrow indicates the time lapse for CA-treated MPX (i.e., 180 s). (C) Measurement of holdase activity by the GFP refolding assay of recombinant MPX (50 $\mu$ M) (squares) and recombinant MPX pretreated with conoidin A (triangles); control (circles) is the spontaneous refolding of GFP. There were no statistical differences between non-treated MPX and CA-treated MPX.

peroxidase vs. holdase activity during the macrophage infection process, we conducted experiments using trypomastigotes preincubated with CA. First, we evaluated the ability of this inhibitor to react with parasite MPX. For this, epimastigotes were exposed to CA $(100 \mu \mathrm{M}, 1 \mathrm{~h})$ and protein extracts subjected to Western blot anti-MPX and anti-CPX under reducing and non-reducing conditions. As shown in Figures 8B, C, nonreducible MPX and CPX adducts were formed in the presence of CA (arrows) as previously described for other peroxiredoxins (Nguyen et al., 2013). This peroxiredoxin CA-induced adducts were stable for at least $4 \mathrm{~h}$; adducts were no longer observed $24 \mathrm{~h}$ later indicating the ability of the parasite to degrade them. Then, CA-treated parasites were used to infect naive macrophages; since the parasite resides in the macrophage phagosome for at least $2 \mathrm{~h}$, peroxiredoxin adducts are still present during parasite internalization in the macrophage phagosome. Finally, CA treatment leads to a significant decrease in the number of intracellular amastigotes following $24 \mathrm{~h}$ of infection (Figure 8D). This means that peroxidase activity of peroxiredoxins is crucial for parasite survival during macrophage infection, reinforcing the importance of the peroxidase activity of peroxiredoxins in parasite resistance and evasion of the macrophage-derived oxidative assault.

\section{DISCUSSION}

The importance of enzymes of the antioxidant network for parasite protection toward exogenous or endogenously derived reactive oxygen and nitrogen species has been previously documented (Piacenza et al., 2007; Piacenza et al., 2013), and in particular, the role of peroxiredoxins in the protection of the parasite against macrophage-derived oxidants has been established (Piacenza et al., 2008; Alvarez et al., 2011; Piñeyro et al., 2011). However, little is known regarding the possibility that, as in other organisms, T. cruzi peroxiredoxins have other roles in dealing with different kinds of stress. Herein, we showed the involvement of MPX in protecting parasites from NFX toxicity. The observations that increased levels of MPX help parasites to overcome the toxicity of NFX (Figures 1A and 2A) and that incubation in these conditions causes overexpression of MPX in wild-type parasites (Figure 3A) but not that of the cytosolic CPX (Figure 3C) clearly indicate that MPX is involved in the parasite protective response toward the drug. Overexpression of MPX was also observed in BZ-treated parasites (Supplementary Figure S4), which may be explained by the fact that BZ metabolism relies on the same mitochondrial nitro reductase NTR-I (as for NFX activation), which means that the mitochondria is the first organelle affected by the action of these drugs (although each drug may have different targets). However, other drugs like ketoconazole and azasterol (McCabe et al., 1984; Goad et al., 1989; Urbina et al., 1995; de Souza and Rodrigues, 2009) that inhibit T. cruzi growth by affecting sterol synthesis did not affect the MPX content in parasites (Supplementary Figure S4). This result points to the conclusion that MPX overexpression is a specific protective response that occurs when the mitochondria is faced with stress.

Since different hypotheses were built in order to explain NFX toxicity, we first assessed the possibility that the ability of MPX to detoxify peroxides was the basis for the observed protection. Nonetheless, we did not observe any evidence of a significant increase in reactive oxygen species production and/or mitochondrial superoxide generation in wild-type parasites treated with NFX (Figures 1B, 2B), so we could not conclude that peroxidase activity explains the protection conferred by MPX toward NFX in this experimental condition. These results are in agreement with previous reports that showed that NFX and BZ are activated by mitochondrial NTR-I in a sequential 2electron reduction steps that does not involve the generation of reactive oxygen species (Wilkinson et al., 2008; Cerecetto and González, 2011).

The protective role of $L$. infantum mitochondrial peroxiredoxin (LimTXNPx) during thermal stress and also 


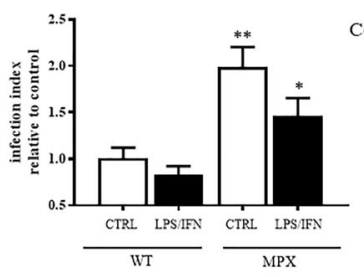

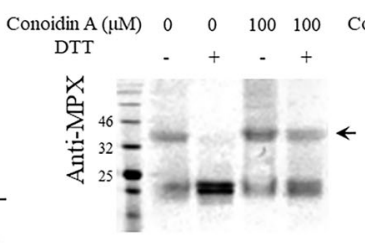

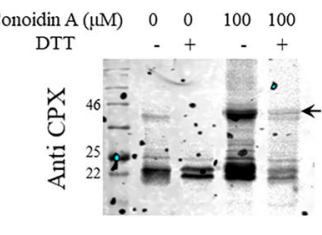

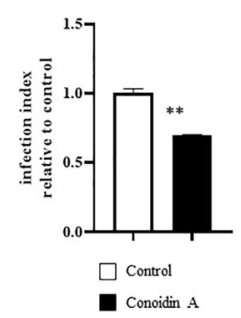

FIGURE 8 | MPX peroxidase activity is required for trypomastigotes to thrive in macrophage infections. (A) Naive or immunostimulated macrophages were infected with culture-derived trypomastigotes (WT or MPX overexpressers) at a parasite:cell ratio of 3:1. Following 2 h, non-internalized parasites were removed and infection proceeded for $24 \mathrm{~h}$. Intracellular amastigotes were counted fluorometrically (DAPI staining) with at least 1,000 macrophages/condition recorded. Results are expressed as the infection index of at least three experiments calculated expressing the number of amastigotes/100 macrophages relative to WT infection. ${ }^{*}$ and * denote statistical differences $(p<0.01$ and $p<0.05$, respectively) with respect to WT control condition. (B, C) Western blot anti-MPX and anti-CPX of protein extracts of culture-derived trypomastigotes treated with conoidin A $(100 \mu \mathrm{M}, 1 \mathrm{~h})$ in DMEM medium at $37^{\circ} \mathrm{C}$. Total protein extracts were obtained as described and samples containing $50 \mu \mathrm{g}$ protein were analyzed by SDS-PAGE (12\%) under reducing (DT, $1 \mathrm{mM}$ ) or non-reducing conditions. (D) Conoidin-treated trypomastigotes [the same conditions as panel (B)] were used to infect naive macrophages as described in panel (A), and intracellular amastigotes were counted following $24 \mathrm{~h}$ of infection. Results are expressed as the infection index calculated expressing the number of amastigotes/100 macrophages relative to WT control. ${ }^{\star *}$ denotes statistical differences $(p<0.01)$.

during macrophage infections was previously proposed. This protective role was fulfilled by the expression of a peroxidase inactive version of the enzyme (Castro et al., 2011). Taking this result into consideration and knowing the ability of T. cruzi CPX to prevent protein aggregation in vitro (Piñeyro et al., 2019), we consider the possibility that the protection conferred by MPX toward NFX may involve the alternative functions of peroxiredoxins, such as the yet unexplored holdase activity.

In this sense, we evaluated the ability of recombinant MPX to aid in GFP refolding and established that in vitro this enzyme increases the rate by which unfolded GFP regains its native structure (Figure 4A). Knowing that holdase activity of several peroxiredoxins is proposed to be modulated by the redox state of the protein, we evaluated MPX holdase activity in its reduced and oxidized state as well as for the catalytic mutant (Supplementary Figure S5). Similar holdase activity was observed in both redox states of the enzyme (Figure 4B), in agreement with what was previously shown for T. cruzi cytosolic CPX (Piñeyro et al., 2019). The observation that recombinant MPX showed holdase activity (Figure 4) prompted us to analyze whether MPX is able in vivo to acquire high molecular weight (HMW) oligomers that are related to holdase activity in other peroxiredoxins, including T. cruzi CPX (Wood et al., 2002; Piñeyro et al., 2019). We found that MPX can acquire this oligomeric structure in the parasite, and interestingly, HMW aggregates are significantly increased in NFX-treated parasites (Figure 5A). These same MPX aggregates were observed in parasites under thermal stress, which suggest a connection between NFX and temperature challenge (Figure 5A).

After establishing that MPX has holdase activity in vitro and that in parasites it can acquire HMW oligomers that increase its abundance in response to NFX, we aimed to study if this is also accompanied by an increase in holdase activity. For this purpose, we measured holdase activity in the HMW protein extracts $(>100 \mathrm{kDa})$ of parasites not treated and treated with NFX. For WT parasites in which an increase in MPX content was observed following NFX treatment, a significant increase in holdase activity with respect to untreated parasites was observed (Figure 5B). This result first establishes MPX holdase activity in vivo and, second, could indicate that parasites increase and activate anti-aggregation systems in response to NFX, suggesting that the drug mitochondrial metabolism may generate a rise in damaged and/ or unfolded proteins. Importantly, the MPX-overexpressing parasites with enhanced MPX content did not show an increase in holdase activity after NFX treatment suggesting that they can deal with the NFX unfolded protein damage response without the need to further increase MPX expression (Figure 5C). We have yet to establish the oligomerization state for MPX and the minimum level of MPX that allows the oligomerization needed to function as a holdase, considering that peroxiredoxins of trypanosomatids seem to have holdase activity in its decameric form (Teixeira et al., 2015; Piñeyro et al., 2019).

To evaluate if NFX causes the unfolding or misfolding of proteins tagging them for degradation, we search for protein ubiquitination and increase in protease activity after NFX treatment of WT parasites. We found an increase in protein ubiquitination and enhancement in proteosome-related protease activity following NFX treatment (Figures 6A, B), which may link NFX toxicity with the increase of MPX expression in WT parasites and the need to gain holdase activity to counteract the toxic effects. The unfolding of proteins could be a consequence of the production of reactive nitriles generated by NFX metabolism by parasite mitochondrial NTR-I, an enzyme that is not found in the vertebrate host (Wilkinson et al., 2008; Cerecetto and González, 2011). This hypothesis is in agreement with the observation that MPX expression increases in parasites grown under thermal stress as previously reported (Pérez-Morales et al., 2012) and as also observed in this work (Figures 3B, 5A). Trypanosoma cruzi life cycle entails multiple changes in environmental conditions such as temperature, $\mathrm{pH}$, and oxidative stress. Parasites have to adapt to these varying environments in order to survive and be able to establish the infection. Besides the antioxidant enzyme system described by our group and others (Piacenza et al., 2008; Piñeyro 
et al., 2008; Piacenza et al., 2009b; Martínez et al., 2019), the parasite has evolved other mechanism to deal with stress such as molecular chaperones, which highlights the importance of maintaining protein homeostasis (Shonhai et al., 2011). The observations reported herein could indicate that NFX alters protein homeostasis in $T$. cruzi causing damage to the mitochondria and that the increase in MPX holdase activity could be part of the response to protein unfolding. The fact that thermal stress, known to require a chaperone response (Sanchez and Lindquist, 1990; Hübel et al., 1997; Jäättelä, 1999), induces MPX overexpression as previously reported (Pérez-Morales et al., 2012) and shown herein supports this hypothesis. Further work is required to characterize the alteration in proteostasis caused by NFX and if this is linked to the toxicity produced by the drug.

Taking into consideration the MPX holdase function described herein, it was considered whether this activity may be of relevance in the context of macrophage infection in which reactive oxygen and nitrogen species are being generated (Alvarez et al., 2011).

In an attempt to disclose the relevance of both MPX activities (peroxidase vs. holdase) and knowing that T. cruzi knockout parasites are extremely difficult to obtain, we evaluate the ability of CA as a possible inhibitor of peroxidase but not holdase activity, since it reacts with the peroxidatic cysteine that is not necessary for holdase activity (Teixeira et al., 2015; Piñeyro et al., 2019). First, we assessed if recombinant MPX reacts with CA which would generate the reported adducts inhibiting peroxidase but not holdase activity. MPX-CA treatment generates the nonreducible protein adducts and inhibits peroxidase activity, but this treatment does not affect MPX holdase activity (Figure 7).

Previous studies from our group have shown the ability of MPX to cope with exogenous or endogenously produced $\mathrm{H}_{2} \mathrm{O}_{2}$ and peroxynitrite (Piacenza et al., 2008), but until now, the potential protection conferred by MPX in macrophage infections is not studied. First, it was proven that MPX contents are important for parasite survival on both naive $\left(\mathrm{H}_{2} \mathrm{O}_{2}\right.$ production) and immune-stimulated macrophages for peroxynitrite generation (Figure 8A). This result is in agreement with MPX peroxidase activity, since inside the phagosome the parasite is exposed to peroxynitrite and $\mathrm{H}_{2} \mathrm{O}_{2}$ that can diffuse inside the internalized parasite reaching the parasite mitochondria (Piacenza et al., 2008; Alvarez et al., 2011), or alternatively, it can be generated inside the parasite by means of the diffusion of its precursors nitric oxide and superoxide radicals (Piacenza et al., 2009a; Martínez et al., 2019). Then, in order to assess the possibility to inhibit MPX peroxidase activity in the parasite, and whether this inhibition may influence T. cruzi ability to establish the infection, we first evaluated if CA generates MPX adducts in vivo. As shown in Figure 8B, CA also generates nonreducible covalent adducts of MPX in vivo similar to the effect observed in the recombinant protein (Figure 7A), indicating that CA is able to act in vivo. Unfortunately, CA acts in both T. cruzi peroxiredoxins, and thus, the unique role of MPX in macrophage infections is not disclosed (Figure 8C). Nevertheless, the role of the peroxidase and/or holdase activities of both peroxiredoxins can be addressed using this inhibitor. We found that CA-treated parasites have a diminished infection index (Figure 8D), showing the importance of peroxidase activity to overcome macrophagederived oxidants in divergence to what was previously observed for $\mathrm{Lm}$ mitochondrial peroxiredoxin (Castro et al., 2011). This result does not discard the fact that MPX holdase activity could be relevant in the infection process. Ongoing experiments are focused on addressing the relevance of MPX in the context of NFX treatment during macrophage infections.

With the observation that MPX is overexpressed in wild-type parasites when exposed to NFX and BZ (Figure 3A and Supplementary Figure S4) and knowing that the mitochondrial metabolism of these drugs gives rise to different toxic and reactive intermediates (Cerecetto and González, 2011; Hall and Wilkinson, 2012; Trochine et al., 2014), we propose that the increase in MPX expression observed may be caused by an enhancement in the modified/damaged macromolecules at the mitochondrial compartment. To further understand if MPX is a direct target for metabolites derived from NFX or if its overexpression is induced by other effects caused by the drug, further experiments need to be performed including the characterization of the adducts observed in Figure 3A. It was previously shown that there is a distinct MPX content among natural occurring strains and that it has a positive correlation with parasite virulence (Piacenza et al., 2009b). Taking into account that MPX overexpression protects parasites from NFX toxic effect (Figure 1), we proposed that the MPX content may be one of the factors that contributes to the differences in NFX sensitivity reported for different T. cruzi strains (Murta et al., 1998).

In conclusion, our results demonstrate that MPX is able to function not only as an efficient peroxidase but also as a holdase, preventing protein aggregation. We observed that peroxidase function is crucial for macrophage infection, but MPX holdase activity may be relevant in other conditions, such as thermal or drug-related stress. We have yet to unravel how these two functions are modulated and which conditions could favor holdase activity. There are many factors proposed to impact on holdase activity of peroxiredoxins, such as redox state, ion concentration, and thermal activation (Wood et al., 2002; Morais et al., 2017; Teixeira et al., 2019). Our results point to the fact that holdase activity of MPX is not related to its redox state. However, given that we observed overexpression and high molecular weight aggregates after thermal stress, it would be interesting to deepen our understanding of the effect of temperature on MPX function during the infection process.

\section{MATERIALS AND METHODS}

\section{Parasite Culture}

Trypanosoma cruzi epimastigotes from the CL-Brener (wild type, WT) were cultured at $28^{\circ} \mathrm{C}$ in brain-heart infusion (BHI) medium as described previously (Piacenza et al., 2001). Parasites overexpressing MPX were obtained as previously described and cultured in BHI containing geneticin (G418, $200 \mu \mathrm{g} / \mathrm{ml})$. Briefly, the complete gene sequences of the enzyme were cloned into the trypanosomal vector pTEX-9E10 (Invitrogen, Massachusetts, United States) and a ligation was performed to insert a c-Myc- 
derived epitope (9E10) in-frame at the $3^{\prime}$ end of the genes to produce the construct pTEX-MPX-9E10 (Wilkinson et al., 2000; Piacenza et al., 2008). Peroxidase activity of MPX was reported to be 1.9 higher in overexpressing cells (Wilkinson et al., 2000). The increase in MPX expression as well as mitochondrial localization of the protein in the transfected parasites ( $\sim 4$ times) is shown in the Supplementary Material (Figure S1).

\section{Growth Curves With Nifurtimox}

Epimastigotes $\left(1 \times 10^{6}\right.$ cells $/ \mathrm{ml}$ starting culture condition) were grown in $\mathrm{BHI}$ medium at $28^{\circ} \mathrm{C}$ for 5 days in the absence or presence of NFX ( $7 \mu \mathrm{M}$, Sigma). The density of the cultures was evaluated by absorbance at $600 \mathrm{~nm}$ every $24 \mathrm{~h}$ (Cary UV-Vis spectrophotometer, Agilent). In order to compare different growth curves, we used the parasite proliferation index in which absorbance at $600 \mathrm{~nm}$ is expressed relative to the $A_{600 \mathrm{~nm}}$ at the first day of the experiments, and the graphs obtained with this index are plotted as mean \pm SD of three independent determinations.

\section{Mitochondrial Membrane Potential}

Rhodamine 123 (RH123, Invitrogen), which accumulates in the mitochondria in a potential-dependent manner, was used as a flow cytometer probe to assess mitochondrial membrane potential. Non-treated parasites $\left(1 \times 10^{7}\right.$ cells $)$ or parasites treated with NFX were washed in PBS and loaded with $5 \mu \mathrm{g} /$ $\mathrm{ml} \mathrm{RH} 123$ for $15 \mathrm{~min}$ at $28^{\circ} \mathrm{C}$, washed in PBS, and analyzed by a flow cytometer (FACS-Calibur, Becton Dickinson). FCCP (trifluoromethoxy carbonylcyanide phenylhydrazone, $1 \mu \mathrm{M}$, Sigma) was used as a positive control for mitochondrial depolarization. In order to compare different conditions, the M1 region of low $\mathrm{RH} 123$ fluorescence (associated with mitochondrial depolarization) was defined.

\section{Dihydrorhodamine Oxidation and BSO Treatment}

After the different treatments, parasites $\left(1 \times 10^{7}\right.$ cells $)$ were collected by centrifugation and incubated for $30 \mathrm{~min}$ at $28^{\circ} \mathrm{C}$ in dPBS containing DHR (50 $\mu \mathrm{M}$, Molecular Probes). Then, cells were washed in dPBS in order to eliminate non-incorporated DHR. Detection of intracellular RH123, the oxidation product of DHR, was performed after exposure to the different experimental conditions using black 96-well plates and a fluorescence plate reader at $28^{\circ} \mathrm{C}$ (Varioskan Flash, Thermo Scientifics) at $\lambda_{\mathrm{ex}}=485 \mathrm{~nm}$ and $\lambda_{\mathrm{em}}=520 \mathrm{~nm}$. Overnight incubation with BSO $500 \mu \mathrm{M}$, an inhibitor of glutathione synthesis, was used to decrease parasite low molecular thiols which reduces parasite ability to detoxify $\mathrm{H}_{2} \mathrm{O}_{2}$ (Thomson et al., 2003).

\section{Low Molecular Weight Thiol Quantification}

Parasite GSH and $\mathrm{T}(\mathrm{SH})_{2}$ levels were quantified in epimastigotes (WT and MPX overexpressers) incubated or not with NFX every day, for 5 days. Parasites were collected and washed in PBS and resuspended at a cell density of $1 \times 10^{9}$ cells $/ \mathrm{ml}$ in $100 \mu$ HEPES buffer (40 mM, pH 8.0) containing monobromobimane $(0.2 \mathrm{mM})$. Following incubation at $70^{\circ} \mathrm{C}$ for $3 \mathrm{~min}$, protein precipitation was performed with methanesulfonic acid (4 M,
$100 \mu \mathrm{l})$ for $2 \mathrm{~h}$ on ice and centrifugation at $13,000 \mathrm{~g}$ for $30 \mathrm{~min}$ was also performed. Non-protein thiols were separated by reverse phase ion-pairing HPLC on an Agilent C18 column and analyzed through fluorometric detection as previously described (Krauth-Siegel et al., 1995). Quantitation and validation were accomplished using $\mathrm{T}(\mathrm{SH})_{2}$ (kindly provided by Luise Krauth-Siegel) and GSH standards (Sigma) and results expressed as $\mathrm{nmol} / 10^{8}$ parasites.

\section{Parasite Extracts and Western Blotting}

Epimastigotes treated or not with NFX (3-5 days) were collected at $2,000 \mathrm{~g}$ for $10 \mathrm{~min}$ at $25^{\circ} \mathrm{C}$, washed, and resuspended in PBS. Lysis was accomplished by freeze and thaw cycles in liquid nitrogen, the extract was centrifuged at $12,000 \mathrm{~g}$ for $30 \mathrm{~min}$ at $4^{\circ} \mathrm{C}$, and the supernatant was collected. For the enrichment in the parasite high molecular weight aggregates, cell extracts of $1 \times 10^{9}$ parasites were filtered using an Amicon ${ }^{\circledR}$ Ultra- $0.5 \mathrm{ml}$ Centrifugal Filter Unit with $100 \mathrm{kDa}$ cutoff.

Parasite extracts were run on polyacrylamide gels (native, $8 \%$ or SDS, $12 \%$ ) under reducing (DTT, $1 \mathrm{mM}$ ) or non-reducing conditions using loading buffer without or with SDS [30 mM Tris-HCl, pH 6.6, 1\% (w/v) SDS, and 5\% (v/v) glycerol]. Loading buffer was added to the supernatant and samples were stored at $-20^{\circ} \mathrm{C}$ until used. Samples were electroblotted into nitrocellulose membranes and equal protein loading was confirmed by Ponceau or Coomassie blue staining. Membranes were blocked in non-fat dry milk (5\% in PBS, $1 \mathrm{~h}$ ) and probed with anti-TcMPX and anti-TcCPX antibodies [kindly provided by Dr. Carlos Robello (Piñeyro et al., 2008)] and anti-ubiquitin antibody (Abcam/ab7780). Reactive proteins were visualized by incubating with secondary antibodies IRE-Dye 800 and/or 680 (LI-COR Biosciences) diluted 1:15,000 (LI-COR Biosciences) and visualized using an infra-red analyzer (Odyssey, LI-COR Biosciences). Band intensity was measured using the program Li-COR Image Studio.

\section{Purification of Recombinant Proteins}

Escherichia coli (BL21 strain) transfected with plasmid containing either His-tagged, MPX, MPX-C81S (mutation of the peroxidatic cysteine), or roGFP (kindly provided by Dr. Shane Wilkinson, Dra. Dolores Piñeyro, and Dr. Marcelo Comini, respectively) both with ampicillin resistance was grown in terrific broth to an optical density at $600 \mathrm{~nm}$ between 0.6 and $0.8 \mathrm{AU}$. The expression of the enzymes was induced by addition to the culture of isopropyl- $\beta$-D-thiogalactopyranoside (IPTG, $1 \mathrm{mM}$ ). Following an overnight incubation at $22^{\circ} \mathrm{C}$, the bacteria were collected by centrifugation at $3,000 \mathrm{~g}$, resuspended in lysis buffer, and sonicated (6 cycles, $1 \mathrm{~min}$ each). The lysate was centrifuged $30 \mathrm{~min}$ at $12,000 \mathrm{~g}$ and $4^{\circ} \mathrm{C}$. The supernatant was collected for purification by affinity chromatography using a nickel column and following supplier instructions (HiTrap Chelating HP, GE Healthcare). Protein elution was monitored by absorbance at $280 \mathrm{~nm}$ and the purity of the fractions analyzed by SDS-PAGE with Coomassie blue staining.

\section{Evaluation of Holdase Activity}

Chaperone activity was evaluated as previously described (Mares et al., 2011). Briefly, green fluorescent protein (GFP) is unfolded 
by incubation with $\mathrm{HCl}(62.5 \mathrm{mM})$ in denaturation buffer [Tris$\mathrm{HCl} 50 \mathrm{mM} \mathrm{pH}=7.5$, containing EDTA $(0.3 \mathrm{mM})$ and DTT $(1 \mathrm{mM})]$ for $1 \mathrm{~min}$ and transferred to freshly prepared refolding

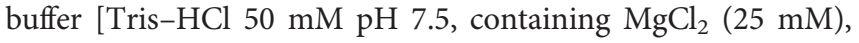
$\mathrm{KCl}(100 \mathrm{mM})$, and DTT $(0.3 \mathrm{mM})]$ at a final GFP concentration of $0.5 \mu \mathrm{M}$. GFP refolding is monitored fluorometrically $\left(\lambda_{\text {ex }}=485 \mathrm{~nm}, \lambda_{\text {em }}=538 \mathrm{~nm}\right)$ using a microplate reader (Varioskan Flash, Thermo Scientific). For the evaluation of holdase activity of recombinant MPX (rMPX), the protein was previously reduced (or not, oxidized state) by incubation with DTT $(1 \mathrm{mM})$ for $1 \mathrm{~h}$. DTT was then removed by Micro BioSpin $^{\text {TM }}$ Size Exclusion Spin Columns (Bio-Rad). Protein was quantified by absorbance at $280 \mathrm{~nm}$, and $50 \mu \mathrm{M}$ of rMPX was used in the assays. For the assessment of the holdase activity in the high molecular weight protein extracts, these were obtained as described from $1 \times 10^{9}$ parasites, and the protein extract obtained $(300 \mu \mathrm{g})$ was used in the GFP refolding assay. Bovine serum albumin (BSA, $50 \mu \mathrm{M})$ that lacks holdase activity was used as control.

\section{Assessment of Peroxidase Activity}

Peroxidase activity was evaluated indirectly by a competition assay between peroxynitrite-dependent oxidation of coumarin boronic acid (CBA, $k \sim 1 \times 10^{6} \mathrm{M}^{-1} \mathrm{~s}^{-1}$; pH 7.4 and $25^{\circ} \mathrm{C}$ ) that yields a fluorescent product (coumarin) in the presence and/or absence of $\operatorname{rMPX}\left(k=1.8 \times 10^{7} \mathrm{M}^{-1} \mathrm{~s}^{-1}\right.$ at $\mathrm{pH} 7.4,25^{\circ} \mathrm{C}$ ) (Piñeyro et al., 2011). Briefly, peroxynitrite released by 3-morpholinosydnonimine hydrochloride (SIN-1, $2 \mathrm{mM}$ ) was determined by measuring DHR oxidation $\left(\epsilon_{500}=78,800 \mathrm{M}^{-1} \mathrm{~cm}^{-1}\right)$ as described previously (Radi et al., 2001). Peroxynitrite-dependent (peroxynitrite flux $\sim 3 \mu \mathrm{M} / \mathrm{min}$ ) oxidation of CBA $(50 \mu \mathrm{M})$ was followed at $\lambda_{\mathrm{ex}}=332 \mathrm{~nm}$ and $\lambda_{\mathrm{em}}=470 \mathrm{~nm}$ in the presence or absence of pre-reduced rMPX $(5 \mu \mathrm{M})$. The decomposition of peroxynitrite by MPX reduces the oxidant generation of coumarin in the first $100 \mathrm{~s}$ (lag phase observed in the presence of $\mathrm{rMPX}$ with respect to SIN-1 condition) and, thus, CBA oxidation.

\section{Proteosome-Related Protease Activity}

Endopeptidase activity was measured using the fluorogenic substrate Suc-Leu-Leu-Val-Tyr-AMC (CAS 94367-21-2, Santa Cruz), and the hydrolysis of this peptide was followed by the fluorescence of AMC (7-amino-4-methylcoumarin, $\lambda_{\mathrm{ex}}=365 \mathrm{~nm} ; \lambda_{\mathrm{em}}=440 \mathrm{~nm}$ ), which is released upon protease activity. Endopeptidase activity in parasite protein extract was evaluated as follows: parasites $\left(3 \times 10^{8}\right.$ cells) were collected after NFX treatment ( 3 days, $7 \mu \mathrm{M}$ ), washed in PBS, and lysed by freeze and thaw cycles; the extract was centrifuged at $12,000 \mathrm{~g}$ for $30 \mathrm{~min}$ at $4^{\circ} \mathrm{C}$; and the supernatant was collected. Endopeptidase activity in the supernatant $(150 \mu \mathrm{g})$ was measured at $28^{\circ} \mathrm{C}$ in buffer Tris- $\mathrm{HCl} \mathrm{pH} 7.4$ by the increase in fluorescence of AMC in a microplate reader (Varioskan Flash, Thermo Scientific). The initial concentration of fluorogenic substrate was $50 \mu \mathrm{M}$.

\section{Parasite Differentiation (Metacyclogenesis)}

Metacyclic trypomastigotes were obtained by chemical differentiation as described previously (Isola et al., 1986;
Piacenza et al., 2009b). Briefly, epimastigotes from a 5-day culture were collected by centrifugation at $800 \mathrm{~g}$ for $10 \mathrm{~min}$ at $25^{\circ} \mathrm{C}$, washed, and resuspended in $10 \mathrm{ml}$ TAU (triatomine artificial urine) [ $\mathrm{NaCl}, 190 \mathrm{mM} ; \mathrm{KCl}, 17 \mathrm{mM} ; \mathrm{MgCl}_{2}, 2 \mathrm{mM}$; $\mathrm{CaCl}_{2}, 2 \mathrm{mM}$; sodium phosphate buffer, $8 \mathrm{mM}(\mathrm{pH} 6.0)$; and sodium bicarbonate, $0.035 \%$ ] at $3 \times 10^{8}$ cells $/ \mathrm{ml}$. After incubation at $28^{\circ} \mathrm{C}$ for $2 \mathrm{~h}$, the parasites were transferred and diluted in TAU3AAG (TAU three amino acids plus glucose) medium (TAU, pH 6.0) supplemented with L-proline, $10 \mathrm{mM}$; Lglutamate, $50 \mathrm{mM}$; L-aspartate, $10 \mathrm{mM}$; and L-glucose, $10 \mathrm{mM}$ to $3 \times 10^{6}$ cells $/ \mathrm{ml}$, following incubation for $96 \mathrm{~h}$ at $28^{\circ} \mathrm{C}$ as described previously (Bonaldo et al., 1988).

\section{Conoidin A Treatment of Recombinant MPX and Parasites}

For the inhibition assays, recombinant MPX was reduced by incubation with DTT $1 \mathrm{mM}$ for $1 \mathrm{~h}$. Then, the reducing agent was removed by Bio-Rad Micro Bio-Spin ${ }^{\mathrm{TM}}$ Size Exclusion Spin Columns (Bio-Rad). Reduced rMPX was incubated with CA $100 \mu \mathrm{M}$ for $1 \mathrm{~h}$, and after incubation, the excess of the inhibitor was removed by Bio-Rad Micro Bio-Spin ${ }^{\mathrm{TM}}$ Size Exclusion Spin Columns (Bio-Rad).

To evaluate the inhibition of parasite peroxiredoxin, epimastigotes or trypomastigotes were collected and resuspended in medium (BHI or DMEM) at a density of $1 \times 10^{8}$ cells $/ \mathrm{ml}$. CA was added up to a concentration of $100 \mu \mathrm{M}$ and incubated for further 30 minutes at $28^{\circ} \mathrm{C}$ (epimastigotes) or $37^{\circ} \mathrm{C}$ (trypomastigotes). After incubation, parasites were washed with PBS, collected, and used in Western blot or infection assays. The ability of CA to crosslink rMPX was evaluated by SDS-PAGE and Coomassie staining under reducing and non-reducing conditions (freshly prepared DTT and/or phosphine, $1 \mathrm{mM}$ ). In parasites, the crosslink was evaluated by SDS-PAGE followed by Western blot anti-MPX under reducing and non-reducing conditions (freshly prepared DTT and/or phosphine, $1 \mathrm{mM}$ ).

\section{Macrophage Culture and Infection}

The murine macrophage cell line J774A.1 [American Type Culture Collection (ATCC-TIB-67)] was cultured in DMEM (Sigma) supplemented with L-glutamine $(2 \mathrm{mM})$, penicillin (100 units $/ \mathrm{ml}$ ), streptomycin $(100 \mathrm{mg} / \mathrm{ml})$, and $10 \%$ heatinactivated fetal bovine serum at $37^{\circ} \mathrm{C}$ in a $5 \% \mathrm{CO}_{2}$ atmosphere.

Metacyclic trypomastigotes obtained as described above were used to infect confluent Vero cells (American Type Culture Collection) at $37^{\circ} \mathrm{C}$ in a $5 \% \mathrm{CO}_{2}$ atmosphere. Culture-derived trypomastigotes were used to infect macrophages seeded in LabTek tissue culture chamber with or without stimulation with IFN- $\gamma(100 \mathrm{U} / \mathrm{ml})$ and LPS $(5 \mu \mathrm{g} / \mathrm{ml})$ in a parasite:cell ratio of 3:1 (Alvarez et al., 2011). After $2 \mathrm{~h}$, no engulfed parasites were removed by washing twice in $\mathrm{PBS}$ ( $\mathrm{pH} 7.4$ ) and cells were further incubated for $24 \mathrm{~h}$ in DMEM at $37^{\circ} \mathrm{C}$. The infected cells were fixed in fresh formaldehyde solution [4\% (v/v) in PBS] for $10 \mathrm{~min}$ at room temperature, washed with $\mathrm{PBS}$, and permeabilized for 5 min with Triton X-100 $(0.1 \%, v / v)$ in PBS. The number of parasites per macrophage was determined by DAPI staining (5 $\mathrm{mg} / \mathrm{ml}$ ). Preparations were analyzed using a fluorescence microscope (Nikon Eclipse TE-200) at a magnification of $\times 100$, 
and digital photographs of infected cells were recorded. At least 1,000 cells from three independent experiments were counted. Results are expressed as the number of amastigotes per 100 cells (\% of infection) relative to the control and represent the mean of three independent experiments. For some experiments, the culture-derived trypomastigotes were preincubated with CA as described above.

\section{DATA AVAILABILITY STATEMENT}

The original contributions presented in the study are included in the article/Supplementary Material. Further inquiries can be directed to the corresponding author.

\section{AUTHOR CONTRIBUTIONS}

GS: cell culture, infection experiments, enzyme activities, flow cytometry and HPLC experiments, data collection, analysis, interpretation, and writing of the article. DE: flow cytometry and HPLC experiments. RR: data interpretation and critical revision of the article. LP: conception and design of the work,

\section{REFERENCES}

Alvarez, M. N., Peluffo, G., Piacenza, L., and Radi, R. (2011). Intraphagosomal Peroxynitrite as a Macrophage-Derived Cytotoxin Against Internalized Trypanosoma Cruzi: Consequences for Oxidative Killing and Role of Microbial Peroxiredoxins in Infectivity. J. Biol. Chem 286, 6627-6640. doi: 10.1074/jbc.M110.167247

Boiani, M., Piacenza, L., Hernández, P., Boiani, L., Cerecetto, H., González, M., et al. (2010). Mode of Action of Nifurtimox and N-Oxide-Containing Heterocycles Against Trypanosoma Cruzi: Is Oxidative Stress Involved? Biochem. Pharmacol 79, 1736-1745. doi: 10.1016/j.bcp.2010.02.009

Bonaldo, M. C., Souto-Padron, T., De Souza, W., and Goldenberg, S. (1988). CellSubstrate Adhesion During Trypanosoma Cruzi Differentiation. J. Cell Biol. 106, 1349-1358. doi: 10.1083/jcb.106.4.1349

Brizuela, M., Huang, H. M., Smith, C., Burgio, G., Foote, S. J., and McMorran, B. J. (2014). Treatment of Erythrocytes With the 2-Cys Peroxiredoxin Inhibitor, Conoidin a, Prevents the Growth of Plasmodium Falciparum and Enhances Parasite Sensitivity to Chloroquine. PloS One 9, e92411. doi: 10.1371/ journal.pone.0092411

Cao, Z., and Lindsay, J. G. (2017). The Peroxiredoxin Family: An Unfolding Story. Sub-Cell Biochem. 83, 127-147. doi: 10.1007/978-3-319-46503-6_5

Castro, H., Teixeira, F., Romao, S., Santos, M., Cruz, T., Flórido, M., et al. (2011). Leishmania Mitochondrial Peroxiredoxin Plays a Crucial PeroxidaseUnrelated Role During Infection: Insight Into Its Novel Chaperone Activity. PloS Pathog. 7 (10), e1002325. doi: 10.1371/journal.ppat.1002325

Cerecetto, H., and González, M. (2011). Antiparasitic Prodrug Nifurtimox: Revisiting its Activation Mechanism. Future Microbiol. 6, 847-850. doi: $10.2217 / \mathrm{fmb} .11 .74$

Da Silva Manoel-Caetano, F., and Silva, A. E. (2007). Implications of Genetic Variability of Trypanosoma Cruzi for the Pathogenesis of Chagas Disease. Cadernos Saude Publica 23, 2263-2274. doi: 10.1590/S0102311X2007001000002

de Souza, W., and Rodrigues, J. C. F. (2009). Sterol Biosynthesis Pathway as Target for Anti-Trypanosomatid Drugs. Interdiscip. Perspect. Infect. Dis. doi: 10.1155/ $2009 / 642502$

Docampo, R., and Moreno, S. N. (1984). Free Radical Metabolites in the Mode of Action of Chemotherapeutic Agents and Phagocytic Cells on Trypanosoma Cruzi. Rev. Infect. Dis. 6, 223-238. doi: 10.1093/clinids/6.2.223 data interpretation, and writing of the article. All authors contributed to the article and approved the submitted version.

\section{FUNDING}

GS and DE were funded by fellowships from the Comisión Académica de Posgrado, Universidad de la República and Agencia Nacional de Investigación e Innovación, respectively. This work was supported by grants from Universidad de la República: Espacio Interdisciplinario (to RR), Comisión Sectorial de Investigación Científica, I+D-2017 (to LP and GS), I+D-2020 (to LP, DE and GS), and Grupos 2018 (to RR). Additional support was obtained from Programa de Desarrollo de Ciencias Básicas (PEDECIBA, Uruguay) and the Uruguayan National System of Researchers (SNI) from ANII.

\section{SUPPLEMENTARY MATERIAL}

The Supplementary Material for this article can be found online at: https://www.frontiersin.org/articles/10.3389/fcimb.2022. 749476/full\#supplementary-material

Docampo, R., and Stoppani, A. O. M. (1979). Generation of Superoxide Anion and Hydrogen Peroxide Induced by Nifurtimox in Trypanosoma Cruzi. Arch. Biochem. Biophys. 197, 317-321. doi: 10.1016/0003-9861(79)90251-0

Estrada, D., Specker, G., Martínez, A., Dias, P. P., Hissa, B., Andrade, L. O., et al. (2018). Cardiomyocyte Diffusible Redox Mediators Control Trypanosoma Cruzi Infection: Role of Parasite Mitochondrial Iron Superoxide Dismutase. Biochem. J. 475, 1235-1251. doi: 10.1042/BCJ20170698

Folgueira, C., and Requena, J. M. (2007). A Postgenomic View of the Heat Shock Proteins in Kinetoplastids. FEMS Microbiol. Rev. 31, 359-377. doi: 10.1111/ j.1574-6976.2007.00069.x

Goad, L. J., Berens, R. L., Marr, J. J., Beach, D. H., and Holz, G. G. (1989). The Activity of Ketoconazole and Other Azoles Against Trypanosoma Cruzi: Biochemistry and Chemotherapeutic Action In Vitro. Mol. Biochem. Parasitol. 32, 179-189. doi: 10.1016/0166-6851(89)90069-8

Griffith, O. W., and Meister, A. (1979). Potent and Specific Inhibition of Glutathione Synthesis by Buthionine Sulfoximine (s-N-Butyl Homocysteine Sulfoximine). J. Biol. Chem. 254, 7558-75560. doi: 10.1016/s0021-9258(18) 35980-5

Hall, B. S., Bot, C., and Wilkinson, S. R. (2011). Nifurtimox Activation by Trypanosomal Type I Nitroreductases Generates Cytotoxic Nitrile Metabolites. J. Biol. Chem. 286, 13088-13095. doi: 10.1074/jbc.M111.230847

Hall, B. S., and Wilkinson, S. R. (2012). Activation of Benznidazole by Trypanosomal Type I Nitroreductases Results in Glyoxal Formation. Antimicrob. Agents Chemother. 56, 115-123. doi: 10.1128/AAC.05135-11

Hübel, A., Krobitsch, S., Hörauf, A., and Clos, J. (1997). Leishmania Major Hsp100 Is Required Chiefly in the Mammalian Stage of the Parasite. Mol. Cell. Biol 17, 5987-5995. doi: 10.1128/mcb.17.10.5987

Hugo, M., Martínez, A., Trujillo, M., Estrada, D., Mastrogiovanni, M., Linares, E., et al. (2017). Kinetics, Subcellular Localization, and Contribution to Parasite Virulence of a Trypanosoma Cruzi Hybrid Type a Heme Peroxidase (TcapxCcp). Proc. Natl. Acad. Sci. U. S. A. 114 (8), E1326-E1335. doi: 10.1073/ pnas. 1618611114

Isola, E. L. D., Lammel, E. M., and González Cappa, S. M. (1986). Trypanosoma Cruzi: Differentiation After Interaction of Epimastigotes and Triatoma Infestans Intestinal Homogenate. Exp. Parasitol. 62, 329-335. doi: 10.1016/ 0014-4894(86)90039-1

Jäättelä, M. (1999). Heat Shock Proteins as Cellular Lifeguards. Ann. Med. 31, 261271. doi: $10.3109 / 07853899908995889$ 
Jang, H. H., Kim, S. Y., Park, S. K., Jeon, H. S., Lee, Y. M., Jung, J. H., et al. (2006). Phosphorylation and Concomitant Structural Changes in Human 2-Cys Peroxiredoxin Isotype I Differentially Regulate its Peroxidase and Molecular Chaperone Functions. FEBS Lett. 580, 351-355. doi: 10.1016/j.febslet. 2005.12.030

Jang, H. H., Lee, K. O., Chi, Y. H., Jung, B. G., Park, S. K., Park, J. H., et al. (2004). Two Enzymes in One: Two Yeast Peroxiredoxins Display Oxidative StressDependent Switching From a Peroxidase to a Molecular Chaperone Function. Cell 117 (5), 625-635. doi: 10.1016/j.cell.2004.05.002

Kim, Y. E., Hipp, M. S., Bracher, A., Hayer-Hartl, M., and Ulrich Hartl, F. (2013). Molecular Chaperone Functions in Protein Folding and Proteostasis. Annu. Rev. Biochem. 82, 323-355. doi: 10.1146/annurev-biochem-060208-092442

Krauth-Siegel, R. L., Jacoby, E. M., and Schirmer, R. H. (1995). Trypanothione and N1-Glutathionylspermidine: Isolation and Determination. Methods Enzymol 251 (1975), 287-294. doi: 10.1016/0076-6879(95)51131-8

Laurent, J. P., Barnabe, C., Quesney, V., Noel, S., and Tibayrenc, M. (1997). Impact of Clonal Evolution on the Biological Diversity of Trypanosoma Cruzi. Parasitology 114, 213-218. doi: 10.1017/S0031182096008414

Liu, G., Botting, C. H., Evans, K. M., Walton, J. A. G., Xu, G., Slawin, A. M. Z., et al. (2010). Optimisation of Conoidin a, a Peroxiredoxin Inhibitor. Chem. Med. Chem. 5, 41-45. doi: 10.1002/cmdc.200900391

Mares, R. E., Meléndez-López, S. G., and Ramos, M. A. (2011). Acid-Denatured Green Fluorescent Protein (GFP) as Model Substrate to Study the Chaperone Activity of Protein Disulfide Isomerase. Int. J. Mol. Sci 12, 4625-4636. doi: $10.3390 / \mathrm{ijms} 12074625$

Martinez, A., Peluffo, G., Petruk, A. A., Hugo, M., Piñeyro, D., Demicheli, V., et al. (2014). Structural and Molecular Basis of the Peroxynitrite-Mediated Nitration and Inactivation of Trypanosoma Cruzi Iron-Superoxide Dismutases (FeSods) a and B. J. Biol. Chem 289, 12760-12778. doi: 10.1074/jbc.m113.545590

Martínez, A., Prolo, C., Estrada, D., Rios, N., Alvarez, M. N., Piñeyro, M. D., et al. (2019). Cytosolic Fe-Superoxide Dismutase Safeguards Trypanosoma Cruzi From Macrophage-Derived Superoxide Radical. Proc. Natl. Acad. Sci. U. S. A. 116, 8879-8888. doi: 10.1073/pnas.1821487116

Mateo, H., Marín, C., Pérez-Cordón, G., and Sánchez-Moreno, M. (2008). Purification and Biochemical Characterization of Four Iron Superoxide Dismutases in Trypanosoma Cruzi. Memorias Do Inst Oswaldo Cruz 103, 271-276. doi: 10.1590/S0074-02762008000300008

Maya, J. D., Repetto, Y., Agosín, M., Ojeda, J. M., Tellez, R., Gaule, C., et al. (1997). Effects of Nifurtimox and Benznidazole Upon Glutathione and Trypanothione Content in Epimastigote, Trypomastigote and Amastigote Forms of Trypanosoma Cruzi. Mol. Biochem. Parasitol. 86, 101-106. doi: 10.1016/ S0166-6851(96)02837-X

McCabe, R. E., Remington, J. S., and Araujo, F. G. (1984). Ketoconazole Inhibition of Intracellular Multiplication of Trypanosoma Cruzi and Protection of Mice Against Lethal Infection With the Organism. J. Infect. Dis. 150, 594-601. doi: 10.1093/infdis/150.4.594

McCall, L. I., and McKerrow, J. H. (2014). Determinants of Disease Phenotype in Trypanosomatid Parasites. Trends Parasitol. 30, 342-349. doi: 10.1016/ j.pt.2014.05.001

McCord, J. M., and Fridovich, I. (1969). Superoxide Dismutase. An Enzymic Function for Erythrocuprein (Hemocuprein). J. Biol. Chem. 244, 6049-6055. doi: $10.1016 /$ S0021-9258(18)63504-5

Meister, A. (1995). Glutathione Biosynthesis and its Inhibition. Methods Enzymol. 252, 26-30. doi: 10.1016/0076-6879(95)52005-8

Morais, M. A. B., Giuseppe, P. O., Souza, T. A. C. B., Castro, H., Honorato, R. V., Oliveira, P. S. L., et al. (2017). Calcium and Magnesium Ions Modulate the Oligomeric State and Function of Mitochondrial 2-Cys Peroxiredoxins in Leishmania Parasites. J. Biol. Chem 292, 7023-7039. doi: 10.1074/jbc.M116.762039

Murta, S. M. F., Gazzinelli, R. T., Brener, Z., and Romanha, A. J. (1998). Molecular Characterization of Susceptible and Naturally Resistant Strains of Trypanosoma Cruzi to Benznidazole and Nifurtimox. Mol. Biochem. Parasitol 93, 203-214. doi: 10.1016/S0166-6851(98)00037-1

Nguyen, J. B., Pool, C. D., Wong, C. Y. B., Treger, R. S., Williams, D. L., Cappello, M., et al. (2013). Peroxiredoxin-1 From the Human Hookworm Ancylostoma Ceylanicum Forms a Stable Oxidized Decamer and is Covalently Inhibited by Conoidin a. Chem. Biol 20, 991-1001. doi: 10.1016/j.chembiol.2013.06.011

Pérez-Molina, J. A., and Molina, I. (2018). Chagas Disease. Lancet 391, 82-94. doi: $10.1016 / \mathrm{S} 0140-6736(17) 31612-4$
Pérez-Morales, D., Lanz-Mendoza, H., Hurtado, G., Martínez-Espinosa, R., and Espinoza, B. (2012). Proteomic Analysis of Trypanosoma Cruzi Epimastigotes Subjected to Heat Shock. J. Biomed. Biotechnol. 2012. doi: 10.1155/2012/902803

Perkins, A., Nelson, K. J., Parsonage, D., Poole, L. B., and Karplus, P. A. (2015). Peroxiredoxins: Guardians Against Oxidative Stress and Modulators of Peroxide Signaling. Trends Biochem. Sci. 40, 435-445. doi: 10.1016/ j.tibs.2015.05.001

Piacenza, L., Alvarez, M. N., Peluffo, G., and Radi, R. (2009a). Fighting the Oxidative Assault: The Trypanosoma Cruzi Journey to Infection. Curr. Opin. Microbiol. 12, 415-421. doi: 10.1016/j.mib.2009.06.011

Piacenza, L., Irigoín, F., Alvarez, M. N., Peluffo, G., Taylor, M. C., Kelly, J. M., et al. (2007). Mitochondrial Superoxide Radicals Mediate Programmed Cell Death in Trypanosoma Cruzi: Cytoprotective Action of Mitochondrial Iron Superoxide Dismutase Overexpression. Biochem. J. 403, 323-334. doi: 10.1042/BJ20061281

Piacenza, L., Peluffo, G., Alvarez, M. N., Kelly, J. M., Wilkinson, S. R., and Radi, R. (2008). Peroxiredoxins Play a Major Role in Protecting Trypanosoma Cruzi Against Macrophage- and Endogenously-Derived Peroxynitrite. Biochem. J. 410, 359-68. doi: 10.1042/BJ20071138

Piacenza, L., Peluffo, G., Alvarez, M. N., Martínez, A., and Radi, R. (2013). Trypanosoma Cruzi Antioxidant Enzymes as Virulence Factors in Chagas Disease. Antioxid Redox Signal. doi: 10.1089/ars.2012.4618

Piacenza, L., Peluffo, G., and Radi, R. (2001). L-Arginine-Dependent Suppression of Apoptosis in Trypanosoma Cruzi: Contribution of the Nitric Oxide and Polyamine Pathways. Proc. Natl. Acad. Sci. U. S. A. 98, 7301-7306. doi: $10.1073 /$ pnas. 121520398

Piacenza, L., Trujillo, M., and Radi, R. (2019). Reactive Species and Pathogen Antioxidant Networks During Phagocytosis. J. Exp. Med. 216, 501-516. doi: $10.1084 /$ jem.20181886

Piacenza, L., Zago, M. P., Peluffo, G., Alvarez, M. N., Basombrio, M. A., and Radi, R. (2009b). Enzymes of the Antioxidant Network as Novel Determiners of Trypanosoma Cruzi Virulence. Int. J. Parasitol. 39, 1455-1464. doi: 10.1016/ j.ijpara.2009.05.010

Piñeyro, M. D., Arcari, T., Robello, C., Radi, R., and Trujillo, M. (2011). Tryparedoxin Peroxidases From Trypanosoma Cruzi: High Efficiency in the Catalytic Elimination of Hydrogen Peroxide and Peroxynitrite. Arch. Biochem. Biophys. 507, 287-295. doi: 10.1016/j.abb.2010.12.014

Piñeyro, M. D., Arias, D., Ricciardi, A., Robello, C., and Parodi-Talice, A. (2019). Oligomerization Dynamics and Functionality of Trypanosoma Cruzi Cytosolic Tryparedoxin Peroxidase as Peroxidase and Molecular Chaperone. Biochim. Biophys. Acta - Gen. Subj. 1863 (10), 1583-1594. doi: 10.1016/ j.bbagen.2019.06.013

Piñeyro, M. D., Parodi-Talice, A., Arcari, T., and Robello, C. (2008). Peroxiredoxins From Trypanosoma Cruzi: Virulence Factors and Drug Targets for Treatment of Chagas Disease? Gene 408, 45-50. doi: 10.1016/ j.gene.2007.10.014

Piñeyro, M. D., Pizarro, J. C., Lema, F., Pritsch, O., Cayota, A., Bentley, G. A., et al. (2005). Crystal Structure of the Tryparedoxin Peroxidase From the Human Parasite Trypanosoma Cruzi. J. Struct. Biol. 150, 11-22. doi: 10.1016/ j.jsb.2004.12.005

Prathalingham Radhika, S., Wilkinson, S. R., Horn, D., and Kelly, J. M. (2007). Deletion of the Trypanosoma Brucei Superoxide Dismutase Gene Sodb1 Increases Sensitivity to Nifurtimox and Benznidazole. Antimicrob Agents Chemother. 51, 755-758. doi: 10.1128/AAC.01360-06

Radi, R., Peluffo, G., Alvarez, M. N., Naviliat, M., and Cayota, A. (2001). Unraveling Peroxynitrite Formation in Biological Systems. Free Radical Biol. Med 30, 463-88. doi: 10.1016/S0891-5849(00)00373-7

Rassi, A., Rassi, A., and Marin-Neto, J. A. (2010). Chagas Disease. Lancet 375, 1388-1402. doi: 10.1016/S0140-6736(10)60061-X

Rhee, S. G., and Woo, H. A. (2011). Multiple Functions of Peroxiredoxins: Peroxidases, Sensors and Regulators of the Intracellular Messenger $\mathrm{H} 2 \mathrm{O} 2$, and Protein Chaperones. Antioxid. Redox Signaling 5, 781-794. doi: 10.1089/ ars. 2010.3393

Rhee, S. G., Woo, H. A., Kil, I. S., and Bae, S. H. (2012). Peroxiredoxin Functions as a Peroxidase and a Regulator and Sensor of Local Peroxides. J. Biol. Chem. 287, 4403-4410. doi: 10.1074/jbc.R111.283432

Saccoccia, F., Micco, P., Boumis, G., Brunori, M., Koutris, I., Miele, A. E., et al. (2012). Moonlighting by Different Stressors: Crystal Structure of the 
Chaperone Species of a 2-Cys Peroxiredoxin. Structure 20, 429-439. doi: 10.1016/j.str.2012.01.004

Sanchez, Y., and Lindquist, S. L. (1990). HSP104 Required for Induced Thermotolerance. Science 48, 1112-1115. doi: 10.1126/science.2188365

Shonhai, A., Maier, A. G., Przyborski, J. M., and Blatch, G. L. (2011). Intracellular Protozoan Parasites of Humans: The Role of Molecular Chaperones in Development and Pathogenesis. Protein Pept. Lett. 18 (2), 143-575. doi: 10.2174/092986611794475002

Sobotta, M. C., Liou, W., Stöcker, S., Talwar, D., Oehler, M., Ruppert, T., et al. (2015). Peroxiredoxin-2 and STAT3 Form a Redox Relay for H2O2 Signaling. Nat. Chem. Biol 11, 64-70. doi: 10.1038/nchembio.1695

Teixeira, F., Castro, H., Cruz, T., Tse, E., Koldewey, P., Southworth, D. R., et al. (2015). Mitochondrial Peroxiredoxin Functions as Crucial Chaperone Reservoir in Leishmania Infantum. Proc. Natl. Acad. Sci. U. S. A. 112 (7), E616-E245. doi: 10.1073/pnas.1419682112

Teixeira, F., Tse, E., Castro, H., Makepeace, K. A. T., Meinen, B. A., Borchers, C. H., et al. (2019). Chaperone Activation and Client Binding of a 2-Cysteine Peroxiredoxin. Nat. Commun. 10 (1), 1-14. doi: 10.1038/s41467-019-08565-8

Thomson, L., Denicola, A., and Radi, R. (2003). The Trypanothione-Thiol System in Trypanosoma Cruzi as a Key Antioxidant Mechanism Against Peroxynitrite-Mediated Cytotoxicity. Arch. Biochem. Biophys. 412 (1), 55645. doi: 10.1016/S0003-9861(02)00745-2

Trochine, A., Creek, D. J., Faral-Tello, P., Barrett, M. P., and Robello, C. (2014). Benznidazole Biotransformation and Multiple Targets in Trypanosoma Cruzi Revealed by Metabolomics. PloS Negl Trop. Dis. doi: 10.1371/journal.pntd.0002844

Trujillo, M., Budde, H., Piñeyro, M. D., Stehr, M., Robello, C., Flohé, L., et al. (2004). Trypanosoma Brucei and Trypanosoma Cruzi Tryparedoxin Peroxidases Catalytically Detoxify Peroxynitrite via Oxidation of Fast Reacting Thiols. J. Biol. Chem. 279, 34175-34182. doi: 10.1074/jbc.M404317200

Urbina, J. A., Vivas, J., Visbal, G., and Contreras, L. M. (1995). Modification of the Sterol Composition of Trypanosoma (Schizotrypanum) Cruzi Epimastigotes by $\Delta 24(25)$ Sterol Methyl Transferase Inhibitors and Their Combinations With Ketoconazole. Mol. Biochem. Parasitol. 73, 199-210. doi: 10.1016/0166-6851(95)00117-J

Wilkinson, S. R., Meyer, D. J., Taylor, M. C., Bromley, E. V., Miles, M. A., and Kelly, J. M. (2002a). The Trypanosoma Cruzi Enzyme Tcgpxi is a Glycosomal Peroxidase and can be Linked to Trypanothione Reduction by Glutathione or Tryparedoxin. J. Biol. Chem. 277, 17067-17071. doi: 10.1074/jbc.M111126200

Wilkinson, S. R., Obado, S. O., Mauricio, I. L., and Kelly, J. M. (2002b). Trypanosoma Cruzi Expresses a Plant-Like Ascorbate-Dependent Hemoperoxidase Localized to the Endoplasmic Reticulum. Proc. Natl. Acad. Sci. U. S. A. 99 (21), 13453-13585. doi: 10.1073/pnas.202422899
Wilkinson, S. R., Taylor, M. C., Horn, D., Kelly, J. M., and Cheeseman, I. (2008). A Mechanism for Cross-Resistance to Nifurtimox and Benznidazole in Trypanosomes. Proc. Natl. Acad. Sci. U. S. A. 99, 13453-13458. doi: 10.1073/ pnas.0711014105

Wilkinson, S. R., Taylor, M. C., Touitha, S., Mauricio, I. L., Meyer, D. J., and Kelly, J. M. (2002c). Tcgpxii, a Glutathione-Dependent Trypanosoma Cruzi Peroxidase With Substrate Specificity Restricted to Fatty Acid and Phospholipid Hydroperoxides, Is Localized to the Endoplasmic Reticulum. Biochem. J. 364, 787-794. doi: 10.1042/BJ20020038

Wilkinson, S. R., Temperton, N. J., Mondragon, A., and Kelly, J. M. (2000). Distinct Mitochondrial and Cytosolic Enzymes Mediate TrypanothioneDependent Peroxide Metabolism in Trypanosoma Cruzi. J. Biol. Chem. 275, 8220-8225. doi: 10.1074/jbc.275.11.8220

Wood, Z. A., Poole, L. B., Hantgan, R. R., and Andrew Karplus, P. (2002). Dimers to Doughnuts: Redox-Sensitive Oligomerization of 2-Cysteine Peroxiredoxins. Biochemistry 41, 5493-5504. doi: 10.1021/bi012173m

Wood, Z. A., Schröder, E., Robin Harris, J., and Poole, L. B. (2003). Structure, Mechanism and Regulation of Peroxiredoxins. Trends Biochem. Sci. 28, 32-40. doi: 10.1016/S0968-0004(02)00003-8

Yewdall, N. A., Venugopal, H., Desfosses, A., Abrishami, V., Yosaatmadja, Y., Hampton, M. B. B., et al. (2016). Structures of Human Peroxiredoxin 3 Suggest Self-Chaperoning Assembly That Maintains Catalytic State. Structure 24 (7), 1120-1295. doi: 10.1016/j.str.2016.04.013

Conflict of Interest: The authors declare that the research was conducted in the absence of any commercial or financial relationships that could be construed as a potential conflict of interest.

Publisher's Note: All claims expressed in this article are solely those of the authors and do not necessarily represent those of their affiliated organizations, or those of the publisher, the editors and the reviewers. Any product that may be evaluated in this article, or claim that may be made by its manufacturer, is not guaranteed or endorsed by the publisher.

Copyright (c) 2022 Specker, Estrada, Radi and Piacenza. This is an open-access article distributed under the terms of the Creative Commons Attribution License (CC BY). The use, distribution or reproduction in other forums is permitted, provided the original author(s) and the copyright owner(s) are credited and that the original publication in this journal is cited, in accordance with accepted academic practice. No use, distribution or reproduction is permitted which does not comply with these terms. 